\title{
Das Nikolsburger Piaristendrama \\ Ein kurtzes Spiel oder Action von Bacchi \\ Geburt Leben vnndt Todt (1654) \\ Kontext - Edition - Kommentar
}

Christian Neuhuber

\begin{abstract}
Aus der ältesten Piaristen-Niederlassung nördlich der Alpen im südmährischen Mikulov / Nikolsburg kommt auch das früheste Theaterstück des piaristischen Schultheaters, das sich nicht nur als lateinische Perioche, sondern (zumindest zur Hälfte) im deutschen Volltext erhalten hat. Der Beitrag bringt die kommentierte Erstedition des Bacchus-Spiels, die die gängigen Vorstellungen von der Spielkultur des Ordens erheblich modifizieren wird. Er erläutert zudem die bemerkenswerten Umstände der Entstehung, Rezeption und Überlieferung, analysiert die ästhetischen Besonderheiten dieser Faschingsunterhaltung und verortet sie im Kontext des barocken Ordenstheaters.
\end{abstract}

\section{Schlüsselwörter}

Piaristen, Barocktheater, Schultheater, Ordensbühne, Dramenedition, Nikolsburg

\begin{abstract}
From the oldest Piarist branch north of the Alps in the South Moravian Mikulov / Nikolsburg, also comes the earliest play by the Piarist school theatre, which has survived not only as a Latin perioche, but (at least its half) in German. The article brings the commented first edition of the Bacchus play, which will significantly modify the current ideas about the order's theatre culture. It also explains the remarkable circumstances of the origin, reception and tradition, analyses the aesthetic peculiarities of this carnival entertainment, and locates them in the context of the baroque religious theatre.
\end{abstract}

\section{Keywords}

Piarists, baroque theatre, school theatre, theatre of religious orders, drama edition, Nikolsburg 
Es war zweifellos ein spektakuläres Bühnenereignis, das am 15. Februar 1654, dem letzten Sonntag vor der Fastenzeit, von der studierenden Jugend des Nikolsburger Piaristenkollegs in Szene gesetzt wurde. Mit Ein kurtzes Spiel oder Action von Bacchi Geburt Leben vnndt Todt stand ein prächtiges Sammelsurium effektvoller Spielmomente von teils heute noch wirksamer Komik und einer doch recht zeitverhafteten Moraldidaxe am Programm, das mit Musik, Tanz und raffinierten Bühneneffekten alles präsentierte, was barockes Theater zu bieten hatte. Doch sollte diese Aufführung eigentlich gar nicht stattgefunden haben, schenkt man den Angaben der älteren Forschung Glauben. Denn die erste Phase des schulischen Schauspiels der Piaristen in den böhmischen Ländern hatte bereits 1641 ein jähes Ende gefunden, als das Generalkapitel in Rom ein Verbot des Theaterspiels an Kollegien, Schulen und Kirchen anordnete und erst 1658 (unter gewissen Auflagen) widerrief (ZEMEK, BOMBERA und FILIP 1992: 138-139). Das Fehlen von Aufführungszeugnissen während dieser Zeit schien bislang die Wirksamkeit der Anordnung zu bestätigen. Dass sich Quellen wie das vorliegende Stück überhaupt finden lassen, ${ }^{1}$ ist letztlich auch ein Indiz dafür, wie wenig man noch von den Anfängen des piaristischen Schultheaters im deutschsprachigen Raum weiß.

Man kann es also getrost als besonderen Glücksfall werten, dass sich das Bühnenmanuskript der Action von Bacchi Geburt Leben vnndt Todt - wenn auch nur fragmentarisch - erhalten hat. Denn es ist - soweit bekannt - die älteste deutschsprachige Schulkomödie des Piaristentheaters, aus der Teile im Volltext und nicht nur in Synopsen der Periochen überliefert sind. Und was sich erhalten hat, weicht doch deutlich ab von den gängigen Vorstellungen, die man vom piaristischen Schultheater der Frühzeit mit seinen pädagogischen und seelsorglichen Implikationen hatte. $\mathrm{Zu}$ sehr hat man es wohl bislang mit den rigideren Strukturen des gegenreformatorischen Jesuitentheaters in Einklang zu bringen versucht. Doch wie schon das piaristische Schulsystem in seinen ersten Jahrzehnten deutlich offener, flexibler, sprachlich und konfessionell toleranter war als jenes der Societas Jesu (BOMBERA 1984: 183), verfolgte auch das piaristische Theater der Anfangszeit andere Prämissen und war anderen Traditionen verpflichtet. Noch nicht das docere stand hier im Vordergrund, sondern das delectare in all seinen Facetten, vom subtilen Humor bis zur derbkomischen Drastik, auch wenn die plakative Abschreckung bis hin zur existentiellen Erschütterung als pädagogische Intention beibehalten bleibt. Anregungen für die szenische Gestaltung holte man sich zunächst weniger beim humanistischen Schuldrama (das auch in den böhmischen Ländern vor dem Dreißigjährigen Krieg eine reichhaltige Tradition aufzuweisen hat) oder bei der gymnasialpädagogischen Konkurrenz (Jesuiten, Benediktiner) als unübersehbar beim italienischen und deutschsprachigen professionellen Theater; aber auch Einflüsse des Fastnachtspiels und anderer laientheatraler Formen sind nicht von der Hand zu weisen.

Die vergleichsweise junge Männerordensgemeinschaft ,Ordo Clericorum Regularium Pauperum Matris Dei Scholarum Piarum' geht auf den spanischen Generalvikar

1 Margita Havličková, die mich vor Jahren auf diese Handschrift der Österreichischen Nationalbibliothek (Sammlung von Handschriften und alten Drucken, Cod. Ser. n. 70) aufmerksam machte, sei herzlich gedankt. Inzwischen ist das Codexfragment auch als Digitalisat online einsehbar, vgl. http://data.onb.ac.at/ rec/AC13910677 [20.06.2019]. 
José de Calasanz (1557-1648, Heiligsprechung 1767) zurück, der in Rom seine Berufung in der Erziehung unterprivilegierter Kinder fand und im Armenviertel Trastevere 1597 eine kostenfreie öffentliche ,Volksschule‘ errichtete. Durch das Breve Ad ea per quae anerkannte Papst Paul V. 1617 die Bewegung als Kongregation, die vier Jahre später durch seinen Nachfolger Gregor XV. zu einem Orden mit feierlichen Gelübden erhoben und 1622 approbiert wurde. Neun Jahre später entstand bereits auf Betreiben des mächtigen Olmützer Kardinals Franz Seraph von Dietrichstein (1570-1636) im mährischen Nikolsburg, seiner Herrschaft, die erste piaristische Niederlassung auBerhalb Italiens. Dort hatte fortan auch das Kapitel der transalpinen Provinz Germania seinen Sitz, dem die Aufsicht über die in den Folgejahren gegründeten Kollegien oblag. Ähnlich wie die Jesuiten und Benediktiner integrierten auch die Piaristen die dramatische Interaktion als eine der wichtigsten Unterrichtsmethoden in ihre Schulpläne, um eine umfassende Wissensvermittlung, rhetorische Ausbildung und moralische Schulung in ,spielerischer' Weise zu erreichen. Zugleich dienten die dramaturgischen Ergebnisse der Außenrepräsentation des Ordens, ohne jedoch - im Gegensatz zu den Jesuiten - in dieser Phase dezidiert auf propaganda fides abzuzielen. ${ }^{2}$

Erste Nachrichten von Aufführungen durch das Nikolsburger Kolleg haben wir aus dem Jahr 1639, als zur Faschingszeit ein Stück eines unbekannten Autors auf dem Programm stand. ${ }^{3}$ Im September darauf wurde die Representation von s. Bonifacii wunderbarlichen Kampff gegeben, ein deutschsprachiges Legendendrama mit lateinischen Interludien, von dem sich eine gedruckte Perioche erhalten hat (HAVLÍČKOVÁ 2011, 2014). Gewidmet war es der Familie des Kardinalsneffen Maximilian von Dietrichstein (1596-1655), der die Aufführung für würdig erachtet haben soll, im Hoftheater in Wien gezeigt zu werden (ZEMEK 1996: 40). Im November 1640 brachten angeblich 70 Kollegschüler anlässlich der zweiten Vermählung des Fürsten die Historia von Joseph dem Patriarchen auf die Schlossbühne, eine mit Ketten verbundene quadratische Bret-

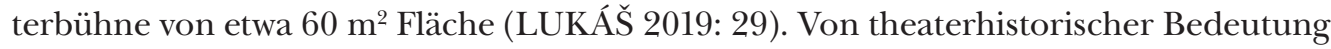
ist diese achtstündige Aufführung allein schon durch die Verwendung von sogenannten Telari oder Periakten, prismenförmigen drehbaren Kulissenteilen für rasche Dekorationsänderungen, die hier erstmals nachweislich in den böhmischen Ländern eingesetzt wurden (NEUMANN 1933: 137). Über den Verlauf der beiden Inszenierungen und ihre außerordentliche Publikumswirksamkeit sind wir durch die Korrespondenz des Nikolsburger Provinzkapitels nach Rom unterrichtet. Dass das Generalkapitel die Theatererfolge so kritisch sehen und weitere Aufführungen untersagen würde, hatten die mährischen Patres offenbar nicht vorhergesehen. Zwar war die reservierte Haltung des greisen Ordensgründers zum didaktischen Mittel des Theaterspiels bekannt, Genehmigungen wurden jedoch erteilt, sofern die Stücke dem moralischen Wohl der Schüler förderlich waren (ENDL 1895: 169f; BOMBERA 1990: 183). Ob - wie Havlíčková vermutet - die Orientierung an Handlungsmustern des italienischen Berufstheaters

2 Zum Piaristenkolleg in Nikolsburg und seiner Theatergeschichte vgl. u.a. (NEUMANN 1933; EIBEL 1967; ZEMEK, BOMBERA und FILIP 1992; KLOSOVÁ 1992; ZEMEK 1996; LUKÁŠ 2014, 2019).

3 Zemeks Hinweis auf eine Opernaufführung von Viettas De recognitione aquitatione im Jahr 1633 kann nur ein Missverständnis sein, vgl. (ZEMEK 1996: 40). 
zu dieser Ablehnung beitrug (HAVLÍČKOVÁ 2014: 207), lässt sich auf Basis der vorliegenden Quellen nicht verifizieren.

In den folgenden Jahren waren die Umstände für öffentliche Aufführungen ohnedies nicht die besten. Die Wirren des Dreißigjährigen Kriegs erreichten 1645 noch einmal Südmähren, als sich schwedische Truppen unter Feldmarschall Lennart Torstensson brandschatzend der Residenzstadt Wien näherten und dabei Anfang April auch Nikolsburg besetzten, plünderten und die Piaristen vertrieben (SCHIECHE 1967). Auch nach ihrer zögerlichen Rückkehr konnte der Fortbestand des Kollegs in diesen bedrohlichen Jahren nur durch die Initiative des Fürsten Maximilian von Dietrichstein gesichert werden. Ihm zu Ehren wird man denn auch die Action von Bacchi Geburt Leben vnndt Todt verfasst und einstudiert haben, auf seinem Schloss wird sie wohl auch zur Aufführung gekommen sein, um das Verbot, in Kolleg, Schule oder Kirche zu spielen, zu umgehen. ${ }^{4}$

Dass wir von dieser Aufführung überhaupt Kenntnis haben, ist einem 38-seitigen Codexfragment $(196 \times 155 \mathrm{~mm})$ zu verdanken, das heute als Cod. Ser. n. 70 in der Sammlung von Handschriften und alten Drucken in der Österreichischen Nationalbibliothek steht und sich aus drei Teilen zusammensetzt: fol. 1 umfasst Titelblatt und Personenverzeichnis, mit fol. 2-5 ist eine lateinische Perioche ohne Titelblatt auf abweichendem Papier eingebunden und fol. 6-38 geben den erhaltenen Rest des Stücks wieder. Wie ein Besitzstempel mit der Amtsbezeichnung ,Nordbahnbeamter auf dem Titelblatt ausweist, wurde die Papierhandschrift (mit anderen Manuskripten aus dem Bestand des Nikolsburger Piaristenkollegs) zwischen 1868 und 1870 vom Stationsassistenten Anton Einsle erworben. ${ }^{5}$ Der Sohn des gleichnamigen Wiener Hofmalers war zu dieser Zeit auf Wunsch seines Vaters bei der Kaiser-Ferdinand-Bahn in Brünn tätig und nützte Ort und Zeit für seine bibliophilen Interessen. ${ }^{6}$ Auf welche Weise er in den Besitz der Manuskripte kam, ist wohl nicht mehr zu klären. Doch gehörten sie zum Grundstock des Angebots, als er nach seiner Rückkehr 1870 mit dem Geschäftspartner Franz Lang das Antiquariat Lang \& Einsle in der Wiener Innenstadt eröffnete (STARL 2016). Über den Zwischenhändler Max Goldschmidt kam das Fragment in einem schlichten Pappeinband dieser Zeit wenig später in die kaiserlich-königliche Hofbibliothek (MAZAL und UNTERKIRCHER 1965: 23), wo es - wohl auch aufgrund seines fragmentarischen Charakters - in den folgenden Jahrzehnten so gut wie keine

4 Konkrete Hinweise auf die Bühnensituation fehlen bedauerlicherweise, zumal sich auch die mit Kreuzchen an manchen Versenden markierten Regiebemerkungen nicht erhalten haben. Doch scheint die Bühne zumindest eine Versenkungsmöglichkeit geboten zu haben, wie der Sturz der Blinden in die Grube bzw. Unterbühne vermuten lässt.

5 Die diesbezügliche Zuordnung war bislang an Mazals und Unterkirchers Fehllesung „Anton Linsle“ gescheitert, vgl. die Webseite der Österreichischen Nationalbibliothek http://data.onb.ac.at/rec/AC13910677 [20.06.2019].

6 Aus Einsles Besitz stammt eine Reihe von Manuskripten und Drucken, die im vorliegenden Kontext von besonderem Interesse sind, entweder aufgrund ihrer Herkunft aus Mähren oder ihres Bezugs zur piaristischen Theaterpflege. Diesen nunmehr in der Österreichischen Nationalbibliothek aufliegenden Bestand berücksichtigen auch (PERNERSTORFER und MALLI 2018b: 144-151) für ihren Katalog der Periochen aus dem Piaristenkolleg in Horn. 
Beachtung fand. Zu Unrecht, denn das, was uns vom Stück überliefert ist, gewährt einen höchst instruktiven und gehaltvollen Einblick in die dramaturgischen Usancen und das durchaus beachtliche Niveau des Schultheaters am Nikolsburger Kollegium Mitte des 17. Jahrhunderts.

Die Action ist in drei Akte zu sechs, sechs und fünf Szenen gegliedert, die jeweils durch ein Zwischenspiel unterbrochen sind. Ein Prolog führt in ebenso unterhaltsamer wie geschickter Weise auf das Thema hin, ein Chor zieht nach der dramatischen letzten Szene ein moralisierendes Fazit; beendet wurde die Aufführung durch einen Epilog, der dem wohlwollenden Publikum dankt, die gemachten Fehler der Akteure entschuldigt und mit Abschiedsworten die Veranstaltung beendet. Wie schon dem Titel zu entnehmen, steht im Mittelpunkt der Handlung Bacchus, der Gott des Weins und der Trunkenheit, der jedoch nicht nur als mythische Gestalt auftritt, sondern als Personifikation auch für unmäßige Sinnenlust steht - ein passendes Thema zumal während der Bacchanalien, der Faschingszeit (die die Schüler im Kolleg verbrachten). Bacchus' Geburt, Leben und Tod bilden als thematische Vorgaben der drei Akte den roten Faden für bewährte Theaterszenen, die beinahe im Revuestil präsentiert werden, sodass sich auch die Zwischenspiele in dieses Tableau der Lasterhaftigkeit nahtlos einfügen. Neben einer erklecklichen Zahl an Teufeln bevölkern schon in der ersten Hälfte des Stücks versoffene Bauern und geldgierige Wahrsagerinnen, zügellose Schmarotzer, faule Studenten und schamlose Bettler die Bühne und werden in zum Teil hochkomischen Betrugskapriolen und burleskem Prügel- und Übertölpelungsslapstick vorgeführt. Obwohl hier die Handschrift abbricht, wissen wir um den weiteren Verlauf aus dem vorangestellten lateinischen Inhaltsverzeichnis: Exzessive Tänze, Arztklamauk, schließlich eine orgiastische Begräbnisszene und ein grauenvoller Blick in die Hölle wurden dem sicherlich beeindruckten Publikum geboten.

Vielleicht ist es ja kein Zufall, dass sich dieser zweite Teil der Handschrift mit gut der Hälfte des Schauspiels nicht erhalten hat. Denn auch wenn die verlorenen Handlungsteile selbstredend allegorisch zu deuten waren mit Bacchus als Sinnbild sündhafter Unmäßigkeit, wäre es durchaus nachvollziehbar, wenn hier von der geistlichen Obrigkeit auf Kloster- oder Generalkapitelebene Bedenken an der allzu anschaulichen Darstellungsweise angemeldet und inkriminierende Partien aus der Vorlage entfernt wurden. Immerhin waren darin für damalige Bühnenverhältnisse und Sehgewohnheiten (zumal auf dem Schultheater!) äußerst gewagte Dinge zu sehen, die freilich für den thematisierten Dionysos-Kult bezeichnend waren: so etwa die hemmungslose Raserei im Tanz, die mit sexuellen und morbiden Konnotationen nicht sparte, oder das omophagische Verzehren von rohem menschlichem Fleisch als ritueller Akt und Götzendienst. Die Herkunft des Theatralen aus eben solch gottlosen, heidnischen Kulthandlungen war seit jeher ein beliebtes Argumentationsmuster, wenn es darum ging, das Schauspiel (zumal in der Pädagogik) zu diffamieren. ${ }^{7}$ Dass auch bereits die unverfängliche Szene 4 des zweiten Akts fehlt, in der die allegorischen Figuren der Fastenzeit, Nüchternheit und Keuschheit ihr Schicksal beklagen, könnte dem Umstand geschuldet

Vgl. u.a. (SCHNUSENBERG 1981). 
sein, dass sie auf derselben fadengehefteten Lage der Handschrift niedergeschrieben war wie die folgende ausschweifende Tanzszene.

Die interessanteste Figur des Stücks ist allerdings nicht der Titelheld, ein autoritärer Hedonist, dem sein Lebensstil zum Verhängnis wird, sondern Zampier, der als komischer Störenfried, Motor und Kommentator des Geschehens handlungstragende ebenso wie narrativ-epische Funktionen übernimmt. Schon im bemerkenswerten Prolog klettert er als vermeintlicher Gast aus dem überfüllten Zuschauerraum auf die Bühne, um in weiterer Folge fiktionsbrechend das Kommando zu ergreifen und den Prologsprecher, der dem Publikum samt Ehrengästen das Stück präsentieren möchte, von der Bühne zu jagen. Seine großspurige Ankündigung „dem Volk vil grösser / Comedi [zu] halten auch bößer" löst er mehrfach überzeugend ein, etwa wenn er die Bettler unter dem Vorwand der Mildtätigkeit um ihre versteckten Geldschätze bringt. Wie für die zentralen komischen Figuren des 17. Jahrhunderts üblich, scheint auch er als zwischen den Spielebenen wechselnder Trickster dem Verderben letztlich zu entgehen, ohne sich in das eingeforderte Tugendsystem zu integrieren.

Obwohl Deutsch die Aufführungssprache des in strengem Knittel gehaltenen Stücks ist, wird mit Latein nicht gespart - freilich nicht in der zuweilen steifen, da am antiken Vorbild orientierten Rhetorik der Jesuitendramen, ${ }^{8}$ sondern zumeist in einer komisierenden makkaronischen Variante, die die Bildungssprache mit der mündlichkeitsnahen Volkssprache amalgamiert. ${ }^{9}$ Beachtenswert ist dabei die Fülle an dialektalen Anklängen, die deutlich über das hinausgehen, was der Leser aus zeitgleichen Drucken an regionalen Eigenheiten der oberdeutschen Literatursprache gewohnt ist. Das Bairisch-Österreichische findet sich in lexikalischen Eigenheiten wie „khei dich hinunder“ $($ keien $=$ stoßen, werfen $)$, ,blodere“ $($ plodern $=$ sprechen $)$ oder „nöchsten“ (= kürzlich, jüngst). Es zeigt sich in morphologischen Spezifika wie der festen Endungserweiterung mit -s in der zweiten Person Plural, die auf das enklitische Personalpronomen "es“ (= ihr) zurückgeht, z.B. in „wartets“ (= wartet) oder „kentz“ (= könnt), und es ist fast allgegenwärtig in der Phonetik, am auffälligsten wohl in der ,Verdunkelung ' des mittelhochdeutschen a-Lauts. Denn dass die überaus häufige graphische a/o-Indifferenz nicht (nur) ein Schreibversehen ist, sondern mehr oder weniger bewusste Wiedergabe authentischer Aussprachegewohnheiten, wird in vielen Fällen auch aus den Reimpaaren ersichtlich, z.B. bei „holen“ / „bezahlen“, „taschen“ / „Groschen“, „kochen“ / „mochen“ etc. Auf andere dialektale Merkmale wie die Entrundung des neuhochdeutschen Diphthongs ,eu“ („Freit eich“), Konjunktivformen mit Dentalsuffix -ad/at wie „gingets“, auf den auffälligen Dativ/Akkusativ-Wechsel („Zeig mir ihm“), Diminutivformen auf -l oder -el („Stinkfisl“), die Konsonantenschwächung („Blerren“ = Plärren), das Verschwinden nebentoniger Vokale und Vorsilben („gton“, „noch gangen“), das

8 Zu grundlegenden Spezifika des Jesuitentheaters sei auf eine aktuelle und online zugängliche Überblicksstudie hingewiesen, die die Ergebnisse einer lebenslangen Beschäftigung mit diesem Thema zusammenfasst, vgl. (RÄDLE 2019). Zur möglichst perfekten Latinität als oberstes Ziel der humanistischen Erziehung in den jesuitischen Ausbildungsstätten vgl. u.a. (RÄDLE 1988).

9 Zur Geschichte und Funktionalität des bairisch-österreichischen Dialekts als ästhetisches Mittel vgl. (NEUHUBER 2015; sowie NEUHUBER, EDLER und ZEHETNER 2019). 
auf m- anlautende Personalprononen der 1. Person Plural („mir“ = wir) oder auch auf archaische Formen wie „kwem“ (= käme) oder „kwomen“ etc. kann hier nur am Rande hingewiesen werden. Mit Sicherheit einen besonderen Reiz hatten für Lateinkundige die komischen Interferenzen durch Homonyme oder Klangähnlichkeiten („fercula“ = Bahre/Ferkel, „filis“ = mit Fäden/viele) oder die latinisierenden Scherzbildungen aus deutschen Wortstämmen mit lateinischer Flexion („In suarcis cuchlis“ = in der Schwarzküche), auch hier wieder im Spiel mit dialektalen Eigenheiten („Klaslia“ = Glasl/Gläser, „Pratlius" = Bratl/Braten etc.)

Der unbekannte Autor des Stücks stammte also mit Sicherheit aus dem bairisch-österreichischen Raum und wird wohl - wie damals üblich - der Rhetorik- oder vielleicht auch Poetikprofessor des Kollegs im Schuljahr 1653/54 gewesen sein. ${ }^{10}$ Seine Arbeit am Stück begann er laut Eintrag ${ }^{11}$ höchst symbolträchtig am Heiligen Abend 1653, schließlich ist Bacchi Geburt Leben vnndt Todt in vielen der vorgestellten Handlungsmomente dezidiert auch als Gegenmodell zu Christi Menschwerdung, Wirken und Selbstaufopferung zu verstehen: Beginnend mit den kontrastierenden Geburtsszenerien eines von einer sterblichen Mutter geborenen Gottessohns über das pervertierte Pfingsterlebnis, plötzlich betrunken in tausenderlei Arten zu sprechen (wie in der Botenrede angedeutet), oder tatsächliche vs. versprochene Wundertätigkeit bis hin zu den antipodalen Sterbemotiven der potentiellen Identifikationsfiguren mit Auferstehung bzw. Höllenfahrt als Konsequenzen ihres Handelns. Beendet wurde die Niederschrift am 19. Jänner 1654, sodass den Beteiligten vier Wochen für die Einstudierung der Spiel- und Tanzelemente, der (möglichen) Gesangseinlagen und der szenischen Ausgestaltung verblieben..$^{12}$

Der Aufführungstermin am 15. Februar 1654 ist nicht zufällig gewählt. Zu ,Dominica Quinquagesimæ‘, dem letzten Sonntag vor der Fastenzeit (im katholischen Süden des

10 Durch die hohe Fluktuation des Lehrpersonals waren auch die Rhetorikprofessoren der Piaristenkollegien üblicherweise nur wenige Jahre durchgehend an einem Ort, vgl. (BOMBERA 1990: 175). Personelle Beziehungen etwa zur niederösterreichischen Piaristenniederlassung in Horn, die 1657 von Nikolsburg aus besiedelt wurde, sind deshalb durchaus denkbar. Zum dortigen Schultheater und Theatrum Sacrum vgl. (PERNERSTORFER 2018; PERNERSTORFER Und MALLI 2018).

11 Die erhaltene Handschrift scheint über weite Teile keine direkte Niederschrift zu sein, sondern - wie aus Zeilensprüngen etc. erkennbar - die Abschrift einer Vorlage, allerdings mit Änderungsfreiheit im Akt des Schreibens. Zwei Schreiberhände sind für diese erste Fassung verantwortlich: Schreiber 1 ist bei zwei Drittel des erhaltenen Teils zu differenzieren (von Beginn bis f. 26v, dann meist nur mehr Szenenbeschreibungen und Überarbeitungen: 29r-29v, 32r Mitte, 34v-35v, 36r-38v), Schreiber 2 übernimmt ab Ende 26-29r, 29v-32r, 32r unten bis 34v, 35v-36r). In einer Überarbeitung von zumindest einer späteren Hand wurden (wohl noch vor der Aufführung) syntaktische Brüche, Reimversehen, Abschreibfehler, stilistische und inhaltliche Problemstellen etc. bereinigt.

12 Im erhaltenen Teil der Handschrift sind zwar keine Gesangseinlagen vermerkt, doch ist ein musikalischer Part allein schon durch die innerfiktionale Betonung der Wichtigkeit von Musikanten bei Feierlichkeiten äußerst wahrscheinlich. Auch die zentralen Tanzeinlagen werden entsprechend begleitet worden sein - ob von Hofmusikern des Fürsten oder etwa von den Schülern des Nikolsburger Loreto-Seminars, muss offen bleiben. Vielleicht holte man sich für die Inszenierung auch Theaterprofis ins Boot, denn noch im Jänner 1654 wurden „commedianten von Nicolspurg“ im nahen Feldsberg von der Kanzlei des (mit Fürst Maximilian von Dietrichstein befreundeten) Karl Eusebius von Liechtenstein zwei Gulden ausbezahlt, vgl. (HAUPT 1998: 58). 
deutschen Sprachraums Faschingssonntag genannt), wurde in den Predigten gerne die von Narren bevölkerte ,verkehrte Welt' thematisiert, um die barocken Leitkategorien der ,Vanitas' (Eitelkeit) alles Irdischen und der notwendigen Jenseitshinwendung zu propagieren. Dementsprechend beliebt war Bacchus als Personifikation der fastnächtlichen Unmäßigkeit zumal im Ordenstheater (vgl. etwa Simon Rettenpachers Juventus virtutis, Joseph Reschs Rhetorica locum invenit in locis rhetoricis oder Maurus Lindemayrs Der Teufel im Faß). Nirgends sonst allerdings ist das Motiv so nachdrücklich wie im Nikolsburger Stück als Travestie auf die Heilsbotschaft zu finden, mit der plakativen Gegenüberstellung von selbstsüchtigem Epikureismus und christlicher Selbsthingabe. Ob das Stück darüber hinaus für einen besonderen Anlass geschrieben wurde, ist bei derzeitiger Quellenlage unklar. Doch könnte Fürst Maximilian nicht nur der obligate Widmungsträger, sondern auch Auftragsgeber der Faschingsunterhaltung gewesen sein. Immerhin hatte er in diesen Tagen einen ausgezeichneten Grund zu feiern und Gäste zu laden. Denn nur zwei Wochen später am 28. Februar 1654 wurde er (in der theaterfreien Fastenzeit) endlich nach langjährigen Verhandlungen - gleichzeitig mit den Fürsten von Auersperg, Piccolomini und Salm - mit Sitz und Stimme in das reichsfürstliche Kollegium aufgenommen. Dass man bei der Vorstellung mit einem vollen Haus rechnen konnte und geistliche wie weltliche Ehrengäste aus Nah und Fern begrüBen durfte, ist schon dem Prolog zu entnehmen.

Das nach Abschluss der Niederschrift nachgetragene Personenverzeichnis nennt die Namen der Kollegstudenten, die auf dem Theater in einer oder mehreren Rollen agierten. 50 Mitwirkende sind zu zählen - möglicherweise alle Inskribierten des Studienjahrs, denn für das folgende Jahr sind 60 Gymnasialschüler verzeichnet (BOMBERA 1990: 172). Anders als bei den Jesuitengymnasien (wo der Anteil an Zöglingen aus höheren Schichten deutlich ausgeprägter war) scheinen die theatralen Aufgaben nicht nach der sozialen Hierarchie vergeben worden zu sein, sondern nach den jeweiligen schauspielerischen Stärken. Auffällig hohen Spielanteil hatten Daniel Nechamb, der nicht nur Prolog und Epilog sprach, sondern auch noch die Arztrolle übernahm, Johann Adam Gruber, der Spezialist für das witzige lateinisch-deutsche Spaßmischmasch, und natürlich die Darsteller von Bacchus (Christopher Kraus bzw. Ludwig König) und vor allem Zampier (Adalbert Hofler). Selbstredend wurden auch die Frauenrollen von den Agierenden übernommen, was gerade bei heikleren Szenen wie den Tanzeinlagen des zweiten Akts für Gelächter oder auch Irritation gesorgt haben mag. Vielleicht wurde die eine oder andere Frauenrolle deshalb auch bewusst vermieden, indem man das dialogische Spiel durch eine monologisch-epische Rekapitulation des Vorgefallenen ersetzte, wie das etwa zu Beginn der Bauernszene der Fall ist. Der von David Olbricht verkörperte trinkfreudige Bauer Jokel, der einem gutgläubigen Bürger die sprichwörtliche Katze im Sack verkauft ${ }^{13}$ und als betrogener Betrüger sein eigenes Geschirr zerschlägt, gehörte sicher zu den traditionsreichen Lachgaranten der Aufführung.

Bei aller Publikumswirksamkeit der fastnächtliche Umkehrung des Normativen ist in der finalen Bestätigung der Ordnung ein schulpädagogischer Wirkeffekt nicht zu 
übersehen: Bacchus und seine Jünger dienen als mahnendes Beispiel den Schülern, die sich nicht mit genug Ehrgeiz den Unterrichtszielen widmen und während der Vakanz den Lastern frönen, ebenso wie den Eltern, die die Faulheit ihrer Kinder noch unterstützen, und allen anderen, die den Freuden des Diesseits zu viel Wert beimessen. Es ist keine unerwartete Lehre, die die Action den Zuschauern hier mitgibt. Doch es kann durchaus als Überraschung bezeichnet werden, mit welcher Gewandtheit, Formenfülle und Theatererfahrung fernab des Herrschaftszentrums eine derart bemerkenswerte Unterhaltung geschaffen wurde.

\section{Bibliografie}

BIBA, Otto. 1975. Der Piaristenorden in Österreich. Seine Bedeutung für bildende Kunst, Musik und Theater im 17. und 18. Jahrhundert. Eisenstadt: Institut für Österreichische Kulturgeschichte, 1975 .

BOMBERA, Jan. 1984. Výchova a vzdělání piaristů v našich zemích. Jižni Morava 20 (1984): 113122.

EIBEL, Zdeněk. 1967. Z dějin piaristického gymnasia v Mikulově 1631-1873. Jižni Morava 3 (1967): 67-75.

ENDL, Friedrich. 1895. Ueber die Schul-Dramen und -Comödien der Piaristen mit specieller Berücksichtigung der dramatischen Aufführungen am Piaristen-Gymnasium zu Horn im XVII. und XVIII. Jahrhundert. Jahrbuch der Leo-Gesellschaft 4 (1895): 167-222.

ENDL, Friedrich. 1896. Die Serie der Schuldramen und Komödien, der Deklamationen sowie anderer Darstellungen beim Kollegium und Gymnasium der Piaristen zu Horn in den Jahren von 1659-1735. Ein Beitrag zur Beleuchtung der Kloster- und Schulbühne Oesterreichs im 17. und 18. Jahrhundert. Mitteilungen der Gesellschaft für deutsche Erziehungs- und Schulgeschichte 6 (1896): 296-316.

HAUPT, Herbert. 1998. Von der Leidenschaft zum Schönen. Fürst Karl Eusebius von Liechtenstein (1611-1684). Wien: Böhlau, 1998.

HAVLÍČKOVÁ, Margita. 2011. Vztahy a vlivy barokního školského a profesionálního divadla na příkladu hry o sv. Bonifáci (Mikulov 1639). In Jan Hojda (Hg.). Náboženské divadlo v raném novověku. Ústí nad Orlicí: Oftis, 2011: 60-67.

HAVLÍČKOVÁ, Margita. 2014. Zu den Beziehungen zwischen barockem Schul- und Berufstheater am Beispiel der Representation Von S. Bonifacii wunderbarlichen Kampff und Lobwürdigen Sieg (Nikolsburg 1639). In Margita Havlíčková und Christian Neuhuber (Hg.). Johann Georg Gettner und das barocke Theater zwischen Nikolsburg und Krumau. Brno: Masarykova univerzita, 2014: 205-215.

HAVLÍČKOVÁ, Margita und Christian NEUHUBER. 2014. Johann Georg Gettner und das barocke Theater zwischen Nikolsburg und Krumau. Brno: Masarykova univerzita, 2014.

[HOLZER, Anton]. 1854. Schuldramen in den Piaristenschulen im 17. und 18. Jahrhundert. Programm und Jahres-Bericht des kaiserl. königl. Gymnasiums in Krems am Schluße des Schuljahres 1854. Krems, 1854: 3-22.

KLOSOVÁ, Markéta. 1992. Dramatika piaristů v 18. století. In František Černý (Hg.). Divadlo v Kotcích. Praha: Academia, 1992: 336-347. 
LUKÁŠ, Miroslav. 2014. Zur frühen Theatergeschichte von Nikolsburg in Mähren (1600-1800). In Margita Havlíčková und Christian Neuhuber (Hg.). Johann Georg Gettner und das barocke Theater zwischen Nikolsburg und Krumau. Brno: Masarykova univerzita, 2014: 183-204.

LUKÁŠ, Miroslav. 2019. Divadlo v Mikulově za éry rodu Dietrichsteinů (od konce 16. století do druhé světové války). Brno: Masarykova univerzita, 2019.

MAZAL, Otto und Franz UNTERKIRCHER. 1965. Katalog der abendländischen Handschriften der Österreichischen Nationalbibliothek: "Series nova" (Neuerwerbungen): Teil 1: Cod. Ser. n. 1-1600. Wien: Prachner, 1965.

NEUHUBER, Christian, Stefanie EDLER und Elisabeth ZEHETNER (Hg.). 2019. Bairisch-österreichische Dialektliteratur vor 1800. Eine andere Literaturgeschichte. Wien/Köln/Weimar: Böhlau, 2019.

NEUHUBER, Christian. 2014. Die vergessene Kunst. Prolegomena zu einer Ästhetik der österreichischen Dialektliteratur vor 1800. Jahrbuch der Österreichischen Gesellschaft zur Erforschung des 18. Jahrhunderts 28 (2014): 53-86.

NEUMANN, Alois Augustin. 1933. Piaristé a český barok. Přerov: Knihkupectví Společenské knihtiskárny, 1933.

PERNERSTORFER, Matthias J. 2018. Vom Heiligen Grab der Pfarre Mödring zum Theatrum Sacrum der Horner Piaristen. Das Waldviertel 67 (2018): 2: 217-234.

PERNERSTORFER, Matthias J. und Rudolf MALLI. 2018. Das Schultheater der Piaristen in Horn. Mit einem Verzeichnis der Aufführungen \& einem Katalog der Manuskripte und Drucke. Jahrbuch für Landeskunde von Niederösterreich N. F. 84 (2018b): 95-263.

PERNERSTORFER, Matthias J. 2019. Wo bleibt die Barmherzigkeit? Oder Allegorische Stücke zur vorösterlichen Bußzeit am Schultheater in Horn (Niederösterreich) im Kontext der Pädagogischen Arbeit des Piaristen-Gymnasiums. Nebst einem Faksimile der lateinischen Perioche des Androtheus von 1722 und deren deutscher Übersetzung durch Alfred Dunshirn. Morgen-Glantz. Zeitschrift der Christian Knorr von Rosenroth-Gesellschaft 29 (2019): 175-222.

RÄDLE, Fidel. 1988. Lateinisches Theater fürs Volk. Zum Problem des frühen Jesuitendramas. In Wolfgang Raible (Hg.). Zwischen Festtag und Alltag. Zehn Beiträge zum Thema, Mündlicheit und Schriftlichkeit: Tübingen: Narr, 1988: 133-147.

RÄDLE, Fidel. 2019. Das lateinische Jesuitentheater in den deutschsprachigen Ländern der Frühen Neuzeit (von den Anfängen bis zum Westfälischen Frieden). Verfügbar online http://hdl.handle. net/11858/00-001S-0000-002D-B657-D [20.06.2019].

RICHTER, Susan. 2007. „Sittliche Schau-Bühn-Spiele“. Die Rolle des Schultheaters im Lehrkonzept des Piaristenordens im 18. Jahrhundert. In Hans Heid (Hg.). Die Rastatter Residenz im Spiegel von Beständen der historischen Bibliothek der Stadt Rastatt. Ein Beitrag zur Geschichte des Piaristenordens in Deutschland. Rastatt: Stadt Rastatt, 2007: 209-228.

RICHTER, Václav, Ivo KRSEK, Miloš STEHLÍK und Metoděj ZEMEK. 1971. Mikulov. Brno: Blok, 1971.

SCHIECHE, Emil. 1967. Umfang und Schicksal der von den Schweden 1645 in Nikolsburg und 1648 in Prag erbeuteten Archivalien. Bohemia 8 (1967): 111-133.

SCHNUSENBERG, Christine C. 1981. Das Verhältnis von Kirche und Theater. Dargestellt an ausgewählten Schriften der Kirchenväter und liturgischen Texten bis auf Amalarius von Metz (a.d. 775852). Eugene: Wipf\&Stock, 1981.

SEHNAL, Jiří, Martin VAŇÁČ und Alena JAKUBCOVÁ. 2013. Franz Fürst von DIETRICHSTEIN. In Alena Jakubcová und Matthias J. Pernherstorfer (Hg.). Theater in Böhmen, Mähren und Schlesien. Von den Anfängen bis zum Ausgang des 18. Jahrhunderts. Ein Lexikon. Neu bearbeitete, 
deutschsprachige Ausgabe. Wien: Verlag der Österreichischen Akademie der Wissenschaften, 2013: 154-157.

STARL, Timm. 2016. Einsle, Anton (1848-1897), Photograph und Buchhändler. ÖBL Online-Edition, Lfg. 5 (25. 11. 2016). Verfügbar online http://www.biographien.ac.at/oebl/oebl_E/Einsle_Anton_1848_1897.xml [20.06.2019].

ZEMEK, Metoděj. 1996. Školní divadlo v Mikulově v 17. a 18. stol. Vlastivědný věstnik moravský 18 (1996): 37-46.

ZEMEK, Metoděj, Jan BOMBERA und Aleš FILIP. 1992. Piaristév Čechách, na Moravě a ve Slezsku 1631-1950. Prievidza: Scholae Piae Prievidza, 1992. 


\section{Edition}

[ÖNB, Sammlung von Handschriften und alten Drucken, Cod. Ser. n. 70]

Ein kurtzes Spiel oder Action von Bacchi Geburt Leben vnndt Todt, weliches durch die Zubereittung eines Schauspiels, von der des Nikolspurgischen Collegij Jugendt exhibirt oder gezeiget wirdt

$$
\langle 1 v\rangle[\ldots]
$$

\section{$\langle 2 r\rangle$ Synopsis seu Compendium}

Totius actiunculæ de Bacchi Nativitate, vita, lucta cum quadragesima, obitu ac tandem damnatione Æterna scenico apparatu à studiosa Nicolspurgensis Collegij Juventute apud Pauperes Matris Dei Scholarum Piarum exhibita Anno à Reparatione Salutis 1654, 15 Febr:

\section{Prologus}

Salutatione humana excipit Auditores, narrans quid in se contineat hæc Actiuncula, vel quid in ipsa futurum sit, quem hospes peregrinus plura dicere nitentem impedit, vnde Prologus offensus conatus illum ex theatro deturbare. Verùm Filij Hospitis auxilium in extremis iam constituto Patri, afferentes, succurrunt, Patrémque vapulantem, fugando Prologum liberant.

\section{$\langle 2 v\rangle$ Actus Primus de Bacchi Nativitate \\ Scena Prima.}

Dæmones convocantes mandato Luciferi ut consilium ineant quibus modis possent homines ad imum Inferni deturbare. Inito tandem consilio, habitúque mutato, omnes in Mundum iter parant, ut ibi mortales per Bacchum à Sobria vita, ad gulam, ebrietatem, vitia, ac tandem ad Tartara, trahant.

\section{Scena Secunda.}

Semele mater Bacchi narrat somnium quod duo explicant Harioli, Zampier versute furatur marsupium Hariolo.

\section{Scena Tertia.}

Tabellarius nunciat Bacchum esse natum admonet omnes ut parent guttura ad celebrandum eius natalia.

\section{Scena Quarta.}

Rusticus ut pecuniam acquirat pro Bacchi solennitate excogitat dolum felem leporis loco sacco inclusum cuidam ciui vendit: pro quo ære Vinum ollosque comparat, quas ebrius dormiendo, perdit ac tandem proprijs (Zampietro sic ordinante) manibus confringit. 


\section{〈3r〉 Scena Quinta}

Bacchus adhuc Juvenis hortatur suos ad constans servitium, futurum ut sempiternum sit eorum convivium. Quadragesima ab omnibus deserta, ab eodem Baccho eiusque pedisequis affligitur.

\section{Scena Sexta}

Tres Studiosi gaudent se accepisse ferias Bacchanalium per triduum, excogitant nouum modum ludendi seque recreandi, lusu finito Bacchum pergunt quæsitum.

\section{Interludium.}

Tres mendici fingunt se orbos, at benè quàm alij homines vident, narrant suas technas \& dolos quibus homines circumveniunt. Ludunt, bibunt vinum exquisitum, saltant ac tandem ad popinam concedunt.

\section{Actus Secundus de Bacchi vita.}

\section{Scena Prima}

Bacchus curat coëmi necessaria pro convivio hospiti〈3v $\rangle$ bus suis benè instituendo: tamen clam hoc famulos exequi iubet. Zampier ne alicui mandatum Domini effutiat, terræ hoc eradit, ut hoc ipsa fideliter servet, ast aliter evenit.

\section{Scena Secunda}

Tres Lumine cassi mendici quærunt Bacchum, quibus ductor illudit. Jactant suas divitias putantes neminem adesse. Zampier uerò illos auscultat, callidè spoliat mutando pallium, pileum \& calceos eorum in quibus ducati insuti sunt.

\section{Scena Tertia}

Famulus Bacchi invitat ad convivium omnes quod Bacchus paravit lautissimum: Enumerat cibos potusque diuersarum sortium. Zampier offam è mensa heri sui subducens filiis constituit prandium quibus comedentibus venit popina pulsus potator qui sinistram fortunam accusat.

\section{Scena Quarta.}

Quadragesima, Sobrietas, \& Castitas exulantes conqueruntur, quas mors consolatur, promittitque se huic exilio finem imposituram.

\section{$\langle 4 r\rangle$ Scena Quinta}

Bacchus prodit cum hospitibus perfecto convivio, quos ut recreat: Saltum curat induci per Zampier \& filios eius, tandem ipse lætitia motus saltui se tradit una cum sociis: verùm nemo potest cessare sonantibus fidibus donec omnes lassi humi serpant Bachusque cum illis: unde contrahit morbum fatalem. 


\section{Scena Sexta.}

Quatuor Luperci ex sodalitate Bacchi lætabundi saltant cum morte, quam ominabantur Virginem, quos ipsa territos fugat.

\section{Interludium.}

Sex iam saturi Rustici consilium ineunt quomodo alleviandus sit stomachus cibis fartus, pro cæna, ut valeant comedere, conveniunt ut probent saltu.

\section{Actus Tertius De Bacchi morte.}

\section{Scena Prima}

Dæmones concurrunt gaudentes se rem bene instituisse hortantes se invicem ad excipiendum Bacchum convinio bonoque balneo in inferno.

\section{$\langle 4 v\rangle$ Scena Secunda}

Medicus aduenit ex longinquis provincijs. Zampier medicamentis medici curatur: Ephebi medicum ad Bacchum ægrotantem invitant.

\section{Scena Tertia}

Medicus nititur curare iam cum morte colluctantem Bacchum: Bacchus moritur: caterua eius defunctum plongit: ventrem aperit, viscera inde consumit, ac tandem sepelit.

\section{Scena Quarta.}

Quadragesima, Sobrietas, \& Castitas, lætantur Bacchum omnium Authorem vitiorum è vivis excessisse: ad sunt nonnulli sociorum Bacchi pænitentes qui malam execrantur vitam proponenter pænitentiam agere.

\section{Scena Ultima}

Dam[n]ati Bacchi anima in inferno conqueritur, maledicit omnibus: Elementa quatuor, Aqua, Terra, ignis Aer eundem accusant, iustitiam Postulantes; Dæmones ipsi damnatum affligunt \& rident.

\section{Chorus}

Indicat omnia esse vana \& finem habitura pessimum cum mundo \& Baccho quæ illi pollicentur.

\section{$\langle 5 r\rangle$ Epilogus.}

Hortatur Auditores Bacchum ut fugiant cuius exitus est tristitia: Gratias agit quod se modestos Auditores exhibuerint: exusat mendos: ac tandem Valedicit.

\section{Finis}




\section{$\langle 6 r\rangle$ Prologus}

Vorred oder Heroldt, thuet die Zueherer höfflich empfangen, mit kurzer erzehlung waß in sich diße Action Begreifet, welcher ein vnbekanter Gast verhindert: warumb der Heroldt Offendirt: will den Gast von dem Theatro hinunderstürzen, aber die Söhn deß Gasts kommen dem geblagten vatter zehilff, vnndt veriagen den heroldt.

Prologus Zampier E̊ duo filij zampetri

PROLOGUS. Ihr Herrn Allesamentlich

Jung, alt, Christlich wie auch weltlich

Euch thun wir Alle Empfangen,

Daß ihr seit herein gegangen,

Der Action beyzuwohnen

Vndt zu vermehren den Nahmen.

Warlich das ist heüt mein Sententz,

Daß der herrn ihre præsentz,

Vnßer Action thut zihren

Das kan man schon klerlich Spieren.

Nicht zwar von wichtigen sachen

Werden mir Comedi machen

Weder von Keysern, Königen,

Oder sonst von einen heilligen

Noch von Fürsten oder graffen

Oder grossen Potentaten

Sondern von Bacchi eitelkeit

Daß er nirgent die Nichterkeit

Halte oder sie halten will

Darumb gret er auf dißes Zihl,

Daß alle Fressen vnd sauffen,

Vndt wie Narren herumb lauffen,

Gott auß den sinn herauß schlagen

Wen sie vol haben den Magen

$\langle 6 v\rangle$ Die Fasten vndt die Nichterkeit

Mit Baccho groß vneinikeit

Widerwertikeit vnndt Schmehen

Müssen leidten auch anstehen

Doch Entlich betribte Fasten

Wirdt schon nicht mehr können Rasten

Die Bößheit Bacchi anschawen

Sondern gänzlich Gott vertrawen

Bachi macht vnd seine Eitelkeit

Zustürzen Biß in Ewigkeit

Vndt von ihr verfürte völcker

Zur Buß vermohnen vil störker 
Alß Bacchus zu vor zum bößen.

Wie er bey Leben gewessen

Waß ist dan das für ein Person

Er ist Ja nicht der dorstenson

Daß er so batzig schickt herein

Er vermeint Ich schenke wein

Ich werde doch ihn fragen vor

Waß er habe zuschaffen dar

Waß wilst? waß suchst gehe herunder

Eß nimbt mich nicht wenig wunder

Daß du ohne erlaubnuß hirher

Kommest nicht anderst alß ein herr?

ZAMPIER. Ey Jüngling ich bitte last mir

Auch zuschawen alhier

Nicht treibet die göst vondannen

Weil sie von weiten herkomen

PROLOGUS. Dißer kan zimblich woll schlesisch

Kanst den nicht teütsch oder böhmisch? $\langle 7 \mathrm{r}\rangle$

ZAMPIER. Teütsch Böhmisch Welisch lateinisch

Türkisch Polnisch vnndt franzesisch

Welisch Bere vnndt mongiare

Polnisch kan ich Gutt vorare

Mit dem teütschen gar wohl trinken

Mit dem Böhmen nicht schlim singen

Spanisch hab ich schon vergessen

Doch möcht ich mit ihnen Essen

Niderlandisch kan ich sizen

Vnndt mit dem Gränlönder schwizen

Türkisch mag ich hier nicht reden

Du kanst mir kein Andtwort geben

Obschon du von hoff bist einer

Glaub mir ich schei mich nicht deiner

PROLOGUS. Ist daß nicht ein große frefenheit

Vnndt in dir merckliche thorheit

Du kommest her kanst nicht die Sprach

Bist warlich würdig einer Straff

Daß du den Anfang verhinderst

Vnndt vnser Ehr alhier minderst.

ZAMPIER. Zur Zeit mus man andre Strassen

Finden, wo sie nicht nein lassen.

PROLOGUS. Sag vor, von wan du komest her?

Oder waß ist hier dein begehr?

ZAMPIER. Verzihe daß soltestu baldt haben

Daß du mich nicht darffst lang fragen.

PROLOGUS. Steig hinab vnndt laß das Blerren

Daß ich red mit denen Herren 
Vnndt mir das Spil baldt anfangen

Dan darauf sie schon verlangen.

Mit Narren mag ich nicht handtlen

Du magst sicher dort hinwandern. $\langle 7 \mathrm{v}\rangle$

ZAMPIER. Hahahaha das ist Ingenium

Wahrlich du hast Judicium

Schaffest mir hinabzusteigen

Gehe hin vnndt thue mirß anzeigen.

Sihest nicht daß ein grosse Menge

Deß Volks sey auch hier gar Enge

Wo soll ich mich dan hinstellen

Glaub daß ich mit villen krellen

Kaum dißes orth hab bekommen.

Solt ich dan so baldt von dannen?

PROLOGUS. Sag an waß ist dan dein Begehr

Oder warumb bist kommen her

Sag an, ich muß baldt auch fort gehen

Mit dir kan ich nicht lenger Stehen

ZAMPIER. Ich wolt einer Comediam

Oder schöner tragoediam,

Auch mit lust alhier anschawen

Weillen kurzweil gefallet mir

Dan eben ich kan solche kunst

Den Bauren machen gar umbsonst

PROLOGUS. Iezt kanstu sicher runder gehen

Deß gleichen wirdt heindt nichts gesehen

$\mathrm{Wa} \beta$ du vermeinst oder gedenkst

Ich habs schon Prophetzeihet lengst

ZAMPIER. In der Statt sagen alle leüth

(Hab ichs vergessen ist mir leyt)

Daß die Studenten alle sambt

Haben verlohren den verstandt

Ist dem also zeig mir es an

Dan ich wolt schon von dannen gan

Ney Ney Comedi werdten sie halten

PROLOGUS. Wie ich sich du thust unß foppen

Vndt vnßer Ehr zimblich Rupfen

〈8r $\rangle$ Gehe hin du Bösewicht du Maußkopf

Gehe an galgen du loßer knopf

Khei dich hinunder \&c

ZAMPIER. Ach ihr liebste Kindelein

Schön wie die Rote Rößelein

Meine treweste Söhnelein

Seyt mit Willkommen nunn Allein

Ist gutt daß ihr seit kommen her

Sonst wer ich nicht lebendig mehr 
Er hött mich alhier erschlagen

Waß hilffts: Ich habs müssen wagen

Jezt wil ich dem Volk vil grösser

Comedi halten auch bößer

Alß sie. Aber daß nicht mein Spil

Welches ich anfangen will

Verhindtert werde von ihnen

Bleibt ihr mir beide dahinnen

Stelet euch baldt zu dißer thür

Vndt ich will warten seiner hir

Wen der Maußkopf wirdt kommen rein

So will ich dapfer schlagen drein

Komm nur Rauß du Kopfmauß

\section{Actus Primus}

\section{Natiuitas Bacchi}

\section{Scena Prima}

Die Teiffel komen zu sammen auß befelh des Lucifer daß sie Rath schlagen durch waß für ein weiß sie könten die leüth in die höll hinab bringen. Nach lan[gem] Rath schlagen kommen sie vberein $\beta$ daß sie Ihre gestalt öndern, vndt auf die welt samentlich gehen. alda d[as] Volk von dem frommen, nüchtern vnd keüschen leben zur fr[esse]rey voll saufferey buberei vnd allen lastern zur lezt[en] aber in die höll zihen.

$\langle 8 \mathrm{v}\rangle$ Carmundius, Tartarius, Belzebub, Pluto, Micros Lunarius

CARMUNDIUS. Adeste Principes Stijges

Belzebub \& omnis Tartari

Vis \& potestas cito cito

Lucifer berus vester Jubet.

TARTARIUS. Waß bedeüt dein Herumb lauffen?

Grosses Geschrey vnd vil schnauffen?

CARMUNDIUS. Tartari du solt es wissen,

Daß ich auß der Höll hab müssen

Auß befehl vnsers Lucifers,

Bald lauffen mit seinen Rewers;

Dan er mir Ernstlich befohlen,

Ich soll eüch allsbald abholen,

Von der Weldt, vnndt zammen Ruffen,

Obschon ihr werdt in der Kuchen

Aber sonst bey der Gasterey

So solt ihr alles lassen frey Nutant capitibus

Vnnd eüch an ein Ort verfigen

(daß ist wahr vnd darff nicht ligen)

Alldar einen Rath eingehen,

Dan es khan gar leicht geschehen, 
In welichen ihr samentlich

Schlissen solt frey vnd ordentlich.

Wie man kent den volg einen geben,

$\mathrm{Da}$ es verlasse daß leben

Welches nichtern ist, gut vnd Rein,

Auch sich von sünden hüttet fein,

Dieses will Lucifer haben

Will vnß auch Reichlich begaben

$\langle 9 r\rangle \mathrm{Daß}$ wir die leüt dar zu bringen

Von Gutten zum bösen zwingen:

Ihnen auch fleisig ein Reden

Daß sie Ewig leben werden

Fressen sauffen vnd turniren

Ihr lebelang Jubilieren.

An den Tot gar nicht gedenken

Gott wirds ihnen alles schenken

Dis mus man ihnen fürschwatzen

Vnd sie Erstlich gar lind Kratzen.

Dan jetzundt die betribte leüt,

Sein schon von bösen gar zu weit,

Weil sie leiden Mieselikeit,

Vnd tegliche tribselikeit.

Dis thut sie zu Gott bekehren

Vnd zum Himmel den Weg lehren.

$\mathrm{Da}$ wir aber dis verhindern

So mussen wir ihnen lindern

Daß scharffe leben auff Erden

Auff daß sie bald vnser werden,

Darumb wil dieses Lucifer,

Vnser allergnedigster Herr,

$\mathrm{Da}$ man die leüt soll betrügen

Vnd mit listen sie bekrigen

Daß sie die Holl bald erspillen

$\mathrm{Da}$ ist sein Eintziger Willen

$\langle 9 \mathrm{v}\rangle$ Nun ihr Herren Allsammentlich,

Gebet Rath ich bitte freüntlich,

Wie man diesen soll nachkommen,

$\mathrm{Da} \beta$ man betrüge die frommen,

Vnndt vnsers Lucifers Willen

Ohne Verzug kan erfüllen.

Herr Belzebub fanget ihr an

Eüch steht dieses ambesten an

Daß ihr vnß einen Rath gebet

Dieweil ihr am lengsten lebet.

BELZEBUB. Da ich Ein mahl wahr in die Welt

Gesandt von dem Höllischen Heldt 
Daß ich den Adam betrüge

Vnnd Euam listig bekrige,

Gottes Gebott zu verlassen

Vnnd wandlen vnsere strassen.

Ist mir nichts bessers für kommen

(Ich habs zwar schon lengst fürgnommen)

Alls daß ich sie mit fresserey

Angreiffen soll Sicher vnd frey,

Vnd bringen darzu in die stroff

Zum Todt vnd dem Höllischen Hoff.

Vil hab ich ihnen zugesagt,

Die Euam Erstlich sehr geblagt,

Goldene berg ihr fürgestellt,

Die man schwer findet in der Welt.

〈10r〉 Sie zum Essen stets Adhortirt

Auch zugeben ihren Haußwirt

Gott wird ihnen nichts drumb sagen

Weder wissen oder fragen

Die Erden hats für geben

Daß die frucht soll gnosseen werden: +

Darzu sprach ich noch ein Wortlein:

Als wie Gott selbst werdet ihr sein.

Auch wissen waß sey Böß vnd Gutt

Oder waß einen schaden thut.

Dis gefill ihnen der massen

Dan sie die frucht alsbald frassen

Die ich Ihnen hab gewisen

Daß sie es keklich genissen.

Die Fresserey in kurtzer Zeit

Bracht ihnen nicht ein schlechten Leidt.

Müsten daß zimblich bezahlen

Daß hat mir wahrlich gefallen.

Obschon noch einer langer Zeit

Seind weck kommen ist es mir leid.

Doch wen wir ietz wen erschnappen

Vnd in Sü[n]den ihn erdappen

Ewiglich thun wir ihm Halten

Im Heisen vnd auch im kalten

Peinigen vnd Ewig Plagen

Gott derffen sie nimmer klagen

Wen auch gleich kwem der Michaël

Oder sein bruder Raphael

$\langle 10 v\rangle$ Ich wolt ihm die Seel nicht geben

Wolt lieber lassen daß leben

Oder ihm vor dicht abschlagen

Mein, er thet mich nicht mehr blagen. 
Dieses wolt ich eüch heüt Rathen

Daß wir daß einzige thaten

Die leüt mit lauter Fresserey

Vollsaufferey vnd buberey

Zur Hölen auff diese Manier

Ziglen. Daß einzig gefalt mir:

Nun Rathet ihr waß sich Reimet

Schilt gleich mit mir wenn ihr meinet.

PLUTO. Dis ist wahrlich ein weise Red

Die eüch Belzebub woll ansteth

Diesen können wir nochkommen

Vnd also fangen die frommen

Aber wer wird gehen in die Weldt

Daß er den Leüten fein nachstellt.

CARMUNDIUS. Von alten Weib fanget ihr an

Vil guts, glaubts mir schaffet man dran

Den Beelzebub schiket ihr hin,

Die gantze Welt wird volgen Ihm.

Er kan sich auch hibsch drein schiken

Durch ihm kan man vil Guts wirken.

Dis thue ich für Guts achten

Doch ihr kentz weiter betrachten

Es ist eüch auch gar wohl bewust

Daß Belzebub mit grossem Lust

Alle Gebott verrichtet hat

$\mathrm{Ob}$ es gleich wahr für oder spat.

$\langle 11 r\rangle$ Daß wird er fleisig verrichten

Weil er khan alles erdichten

Dan die leüt ietzund in der Welt

Trachten ammeisten nach dem Geldt

Fressen sauffen vnd vnkeüscheit

Verwerfen gantz die Nichterkeit

Daß böse thun sie mehr achten

Daß Gutte nimmer betrachen

Drumb muß man sie confirmiren

Vnd zum diesen Adhortiren.

Herr Belzebub wir bitten dich

Allein erstlich erhöre mich

Geh auff die Weldt zu Einen Weib

Moche dir auß der lufft ein leib.

Schwatze ihr etwaß kürtzlich für

Sie wirds glauben vnd volgen dir

Lehre sie Etliche Kinstlein

$\mathrm{Zu}$ machen auß dem Wasser Wein

Vnd auß striken müllich mälken

Vnd andre leüt vieh erwirken 
Sie wird ein guttes instrument

Durch sie bringen wir als zum End

Durch sie wird verfirt die Jugent

$\mathrm{Zu}$ Verlassung alle tugent

Auch wo mir nicht selber kommen

Kan daß alte weib hin Rennen.

BELZEBUB. Nein Nein dis kent ihr tentiren

Vnd alte Weiber Probieren.

Geht hin ich bin ihrer schon satt

Mit diesen kommet ihr heüt spat.

$\langle 11 v\rangle$ Dan sie mich zimblich durch glassen

Nachsten nicht weit von der strassen

Dortwo sie ihren dantz hilten

Vnd mit einander lang Spilten

Ich hett mich auch darzu wöllen

Nur auß Kurtzweil zugesellen

Auwe wie Eng ist die schantzen

Mier gewest, mein ich hab dantzen

Müssen vber Gruben vnd zein

Es hat bald kost daß leben mein.

Gehabt eüch wohl ich geh dar von

Ich beger nicht Eweren lohn

Auff die welt mog ich nimmer gehn

Dan ich müst vil böses ausstehn

Villiber laß ich mich henken

Oder in dem Meer Ertrenken.

PLUTO. Herr Belzebub nicht eilet sehr

Erzirnet nicht Sondern kombt her

Anders können wir es machen

Weilen dis sein gringe sachen

BELZEBUB. Ich mecht eüch Rathen ihr Herren

Wen Ihr vnser macht welt mehren

Last alte weiber beseiten

Auff den Krücken allein Reiten

Sie werden balt all zusammen

In vnsere Herschafft kommen

In der Welt wir alle können

Den leüten fleisig nachstellen

〈12r〉 Dann ihr virr mehr dort außrichten

Als ihm einer kind erdichten

CARMUNDIUS. Diesen können wir nach kommen

Wie mir von ihm han vernommen,

PLUTO. Dis thue ich virs Gut achten

Vnd bin bereit mit eüch zu gehn

BELZEBUB. Mit diesen bin ich auch content

An mir hats zwar kein Mankement 
Kombt mir werden leüt betrigen

Auff daß mir sie bald her krigen

Fressen sauffen vnd vil sünden

Muß man ihnen fleisig finden

Dardurch zur Höllen abzihen

Mit bösen allzeit bekrigen.

Wen wir dir dis volbringen werden

Daß volg betrigen auff Erden

So wird vnß gegeben ein lohn

Von Lucifer guldene Kron.

CARMUNDIUS. Es geschehe wie ihr wöllet,

Vnd eüch alle darzu stellet.

Ey so gehn wir bold auff die Welt

Weil wirs haben also bestelt

Doch, er wir vnß drauff begeben

So ists voneten beyneben

Die Gestälten hier verkehren

$\mathrm{Da} \beta$ vnß die leüt nicht erkennen

Auch mit ihnen wir gut handlen

Jeder welt leben vnd wandlen. $\langle 12 \mathrm{v}\rangle$

PLUTO. Ey so wartet ein klein wenig

Auff den weg bin ich schon fertig

In die Höll will ich gleich lauffen

Vnd eüch neüe Kleider kauffen

Auff das wir allso vnbekant

Durch ziehen mögen alle land.

CARMUNDIUS. O Herren nun kennen wir gehn

Daß Kleid wird vnß gar wol anstehn

Niemand wird vnß dort erkennen

Weder vnß bey Nahmen nennen

Vnd wen gleich vnser Lucifer

Selt iezund selber kommen her.

Ey so kombt ihr Herrn.

\section{Scena Secunda}

Semele Mutter Bacchi Erzehlet ihren schwaren traum, welichen zwey Zigeiner auß legen. der Zampier stilt einer Zigeinerin arglistig den beütel mit dem Geldt.

Semele, Haczala Raczala, Zampier

[SEMELE.] Ach wie leid ich große S[ch]mertzen,

In meinen betribten Hertzen

Dan die Engsten mich antasten

Lassen mich weder außrasten

Sie blagen mich bey Tag vnd Nacht

Dar wider find ich gar kein Wocht. 
Ach wem sol ich dieses klagen

Oder wem betrübte fragen,

Wem soll ich mein Traum erefnen

Daß ich von ihm könte Lernen

$\langle 13 r\rangle \mathrm{Wa} \beta$ er bedeüt oder mit bringt

Weil er so sehr in Ohren klingt

O Jupiter ich bitte dich

Gantz betrübte erhöre mich,

Mein Gebet heüt nicht verwerffe

Sondern mir den traum ereffne

Schike mir einen gelerten Mann

Der die treüm fein außlegen khan

Dardurch mein Hertz erlustige

Ich bitte thu daß jenige.

Wen du mich dan nicht erhörest

Sondern mein Gebet verwerffest,

So muß ich hier gantz verderben

Dar zu Elendiglich sterben.

Der Traum blagt mich der Traum krenkt mich

Vmb Hilff o Jupiter bitt ich

Daß ich des Traumes beschwerung

Kleine [mög haben] erklerung.

Dort hab ich etwaß wahr gnommen

Daß hir her frembde Leüt kommen

Aber sie sein gar wunderlich

Vnd in den gsichtern gantz greilich.

Doch wil ich sie vor befragen

Vnd zu ihnen freündlich sagen,

Waß sie suchen oder wöllen

Oder Entlich waß sie können.

Gegrüsset seitt ihr alle beid

Ich Erken ihr seid frembde leütt

〈13v〉 Zeiget mir an ohne Verzug

Trewlich, willig, vnd ohne lug

Ich wolt gern etwaß Newes

Von eüch erfahren doch trewes

Dan ich merk daß ihr frembde Leüt

Alher vnter vnß kommen seit.

RACZALA. Ach Frewelein mein Hertzelein

Du allerschönstes blimelein

Ich kenne dich mein taübelein

$\mathrm{Da} 3$ du trew bist mein Röselein

Höre ich wil dirs bald sagen

Darffst weiter keinen mehr fragen

Du bist ein fraw in dieser Welt

Der gantz nicht manglet an dem Gelt 
Du bist möchtig vnd volkommen

Bist auch weit vber die frommen,

Du bist die schönste vnd nicht grob

Ist dir daß nicht ein schöne lob.

Du bist mild, du bist auch gittig

Allen Menschen barmhertzig

O Frawe du liebest alle Leüth

Dein lob strekt sich auß weit vnd breit

Du hast, du hast, grosse Schmertzen

In deinen betrübten Hertzen

Dust dicht zwar zimblich beklagen

Derffst aber nimanden sagen,

Sag an sag an hertzlibste fraw

Dein schweres Hertz nur mir vertraw

Ich will dir alles außlegen

Darfür darffst vnß nicht vil geben $\langle 14 r\rangle$

SEMELE. Wie Soll ich dieses verschulden

$\mathrm{Daß}$ ich heüt erhört bin worden

O Jupiter du grosser Gott

Geschicht mir von dir grosse gnad

Mein Gebet hast du erhört

Vnd trawrikeit in Frewd verkert

Hast mir auch zu gsicht diese leüt

Die mich zu trösten seind bereit.

HACZALA. Fraw waß dich krenket zeig es an

Wons gleich dein leben ginget dran,

Wie sich gebirt werden wir dir

Alles außlegen glaube mir

Daß kan ich vor dir nicht laugnen

Dan ich gsichs auß deinen Augen

$\mathrm{Da} \beta$ du fromb bist vnd allen trew

Daß Red ich vor männiglich frey.

Zwar du hast ein betrübtes Hertz,

$\mathrm{Da}$ ist wahr, vnd ist kein schertz

Sog an waß dich kränket so sehr

Daß du nicht geblagt werdest mehr

SEMELE. Weilen ich eüch hier allebeid

Sehr willig sehe vnd bereit

$\mathrm{Zu}$ mir vnd meinen Glickh geneigt

Wen ichs verschwig wer es mir leid

Ewer warheit ich Erkenne

Weilen ich von eüch vernemme

Daß entweder Wahrsagerin

Ihr seit oder Weisagerin

$\langle 14 v\rangle$ Heret nun ich wil eüch sagen

Vnd meine Anligen klagen 
Es hat mir getraumbt negste Nacht

$\mathrm{Da}$ Jupiter mit grosser mocht

Sey kommen zu meiner wohnung

Mir zugeben eine lobung

Zwar sein licht vnd grosse Klarheit

Kunt nicht dulden meine schwacheit.

Sondern ich fil bald zur Erden

Vnd kund nicht mehr gesund werden

Wie daß geschah so nemmet wahr

Da ich allso schon gantz tod wahr

Ist Jupiter zu mir kommen

Vnd hat waß auß mir genommen

Hats verstekt in seine lenden

Vnd wolt sich von mir weg wenden

Aber über eine kleine Zeit

Hab ich gesehen allbereit

$\mathrm{Da} \beta$ er daß wiederum Rauß genommen

Secht Wunder sein mir für kommen

Lauter Perlen vnd schmaragden

Carbunclen vnd Diamanen

Die warff er in die gantze Welt

Ich meint daß er einen nachstelt

Aber die selbige steinlein

Gaben von ihnen grossen schein

Alles den menschen wohl gefelt

Waß sich nur bewegt in der Welt

Jung vnd alt wahren freüden vol

Ja maniche narrisch vnnd Toll

Frewten sich all samentlich

Daß ihnen Jupiter Reichlich

$\langle 15 r\rangle$ Außtheilet so schöne sachen

Welche die Welt nicht khan mochen

Dis thet ich nun gern erfahren

Wen du mir thetest erkleren

Waß der traum mit sich thut bringen

Daß er nun auffhöret klingen

In meinen Ohren vnd sinnen

Daß ich kent bösen entrinnen

Ist der traum gut so sog es gleich

Darumb wirst du belonet Reich

Finff Hundert wil ich dir geben

Wen den traum wirst gut außlegen

RACZALA. Gar gut gar gut mein Röselein

Mein Allerliebstes frewelein

$\mathrm{Zu}$ vor must du einen groschen

Außnemen auß deiner taschen 
Vnd legen auff dein weise Hand

$\mathrm{Daß}$ ist schon lang vnsers benant.

Wahrlich fraw du wirst lang leben

Dis Zeichen thut dirs fürgeben

Vil hast auch müssen schon leiden

Vnd böse leüt effter meiden

Desen bist allen Entgangen

Hat dich niemand kennen fangen,

Dieses thut dein traum andeiten

Vnd wil dich zum Grab begleiten

Aber noch vielen Jahren erst

$\mathrm{Da} \beta$ end des leben haben werst

Doch die Perlen vnd Edelstejn

Glaub daß groß Geheimnus sein

$\langle 15 v\rangle$ Du wirst einen Sohn Empfangen

Vnd dardurch den tod erlangen

$\mathrm{Daß}$ du wirst müssen hin scheiden

Die leüt vnd auch die Welt meiden.

Der Höchste aber Jupiter

Vnd in der Welt eintziger Herr

Er wird daß Kind auß deinen leib

(Glaub mir O du Ehrliches Weib)

Außnemben vnd selbst behalten

$\mathrm{Daß}$ selbige nicht verachten

Sondern fürstellen auff die Welt

Als wie ein Ritterlicher Heldt

Daß Kindlein werden alle Leüt

Ehren vnd Loben weit vnd breit

Letztlich in wenigen Wochen

Einen König auß ihm mochen,

Er wird die Welt ziemlich ziren

Daß wird man mit der Zeit Spieren.

Dis bringt mit sich der traum allein

Doch must du nicht drumb trawrig sein

Daß du wegen Sohns must sterben

Dan er ein König wird werden

Dardurch wirst groß Lob erwerben

Wer acht den todt wirst leicht sterben

SEMELE. Ach wie hast mein Hertz gelindert

Vnd meine schmertzen gemindert

Den todt veracht ich gantz vnd gar

Mein Sohn wird König daß ist wahr

〈16r〉 Komb folget mir in dieses Hauß

Dorten will ich eüch zohlen auß

Keinen Geld wil ich nicht schenken

Der Traum wird mich nicht mehr kränken 
ZAMPIER. Ha, Ha, Ha, Ha, ich thu eüch glauben

Weil ich eüch khan braff berauben

Ihr Kint leüten treüm außlegen

Zum vilen sachen bewegen

Wissen auch kinfftige Gsichten

Die vielleicht gschehen mit nichten

Doch ewers beütels vergesset

Ja wohl gar nichts dar von wisset,

So ist es gut auß der mossen

Diese Narren Rathen lassen

Sie mit dieser Kunst betrigen

Beütel Gelt von ihnen kriegen.

Jetzt wil ich von eüch weiter gehn

Kan schon allhir nicht lenger stehn

Ich wil mir suchen ein Gespan

Der mit mir heüt gut trünken kan

Mich auch bey leüten Respectirt

Vnd Effter Kläslein Præsentirt

Dis Gelt wil ich deputiren

Vnd der schänkin offeriren

Wen aber wird der beütel Lehr

So such ich bey Zigeinern mehr.

\section{$\langle 16 v\rangle$ Scena Tertia}

Ein Bott bringt newe Zeitung daß der Bacchus sey Schon gebohren, destwegen Soll iedweder sein Geburt fewerlich halten.

NUNCIUS. Bottius ex frembdis huc mittor credite Landis

Zeitungis lætis varijs schreibisque granatus

Freit eich ihr populi freit eich mea turba sodales

Et vos bursta studentorum quia festa Lyaei

Schon commen vobis bene nota pratelia dudum.

Ergo parate hodie Pauchos purgateque maulos

Guttura cum dermis aptus sit magius æque

Pro Speisis epulisque filis \& in ilia Claslis

Fundendis, auf das heit seint bene cuncta parata.

Tischticher in mensis, teller, saltz, inque culinis

Omnia sint fertig in aquis sit frischius haustus,

Pocula plena mero nec manglet martia birra.

Heit audite nova ist der Bacchus in Vrbe geboren

In suarcis cuchlis gleich tempore finstere noctis

Bold damals ui der Titan extulerat ortus.

Non tamen herr Bacchus misera prodiuit in æde

Veder in abiectâ Baurorum duxerat ortus

Summa fuit Baccho der G[e]burt glaubt alle culina: 
Quâ dum prodiret simul atque palatia regum

Scanderet, ecce tubæ taratantara Tympana bom bom

Reddebant, gaigis, citrisque alij omnia Lautis

Complebant, decorantes diademate natum.

Hic mihi gab mandat, per compita perque plateas

Spargam ut zeitungas allis durch orbita Leitis

$\langle 17 \mathrm{r}\rangle$ Quis mihi nunc plenis uortorum millia saccis

Hic feret, ut memorem, neben uan fata tulissent

Zuherern, tantis uidissent pectora gestis,

Quæ præ multis non possum dicere uortis

Intellexistis naias mea turba zaitungas?

Plus thet ich eich sagen ven ich abscedare nicht selt

Dan alles curcis non possum dicere verbis,

Iam scitis for hin quid talia festa reposcant,

Hoc faciat ieder cui fraile pecunia dienet

Omnibus in Craemis fleisig sei pocula leuando.

Et si quis caret ære graui simul atque paratis

Nummis dem potius rath ich zu bleiben in hause

Nec præsumat inops loden ad pocula Bacchum

Sondern amittet multos de uertice crines

Cum socijs minimè poterit si pocula zalen.

Iam celebrabo etiam exsiccando hic pocula Kirmes,

Hei kombt her Domini, dar ist ein frischius haustus,

Doch prius ex nostris sumemus fercula saclis,

Pratlius hic habitat manet \& cum bursta caponus,

Ei prodi captiua foras mea flaska bibemus

Attamen auff Guttes bislein est illa monenda

Skilt domini à tutti, nostras replete polabras

Nur hodie, nam ego iam sapientior omnibus exto

Quod mea trincauit iungum de more falernum

Lingua, mihi subito hæc parlandi mille ministrat

Mille modos sag ich quos mens mea calluit unquam.

Oho iam mea sunt Speisis satis ilia farta

En satus ich laufe hei hei hei bona turba valete

Ey ey waß ist daß? Waß ist daß?

O fortuna ferox uorumb uerderbst mea pocula.

\section{$\langle 17 v\rangle$ Scena Quarta}

Ein Bawer daß er Geldt bekomme auff die Fastnacht, Listiglich thut er ein Katz in Sack einem Burger verkauffen, für daß Gelt thut er Häffen kauffen vnd Wein weliche Haffen er voll schlaffend verlirt, vnd nocher selbsten (dan der Zampier stelts allso an) mit eigenen Händen auff kleine stüklein zerschmetert.

Jokelius Polyphilus Ẽ Zampier 
JOKELIUS. Gestern hab ich eins vernommen

Wie ich von Aker bin kommen

Von Weib vnd aüch von anderen

$\mathrm{Da}$ Bacchus sey schon auff Erden

Zur welicher festivitet

Oder Bacchi solennitet

Burger Herren vnd Edeleüt,

Arme Reiche vnd gmeine leüt,

Sollen sich alsbald drauff machen

Die grosse frewd nicht verlachen

Sondern mit grosser Höfflikeit

Sie begehen, vnd Erbarkeit.

Wie ich dieses hab vernommen

Ist mir zimblich vmbgegangen

In meinen Kopf vnd in dem Sinn

Ich wust nicht wo ich solte hin

Vor Kommer vnd grossen schmertzen

(Ich sog wahr vnd thu nicht schertzen)

$\langle 18 r\rangle$ Ich wust auch nicht waß für sachen

$\mathrm{Zu}$ diesen tisch man sol machen,

Dan ich bin arm vnd bin nicht Reich

Daß beken ich keklich vor eüch.

Darauff fragt ich auch bald mein Weib

Ich gsah daß ihr dis wahr sehr leid,

$\mathrm{O}$ weib waß werden wir mochen

(Sogt ich) mir han nichts zu kochen

Als wenig linsen vnd Kruppen

Welche taugen nur zur suppen

Vnd ein tägliches sawr Kraut

$\mathrm{Zu}$ erfillen vnsere Haut

Doch daß alles waß wir haben

Tet ich allein als begraben

Vnd in kurtzer Zeit verzehren

Darzu Sechs bind Wein begehren.

Darzu sprach mein witziges Weib,

Du sorgest nur vmb deinen leib.

Kinder vnd des weibs vergessest

Auch in daß Hauß gar nichts kauffest,

Es ist zwor wahr daß wir droben

Noch Etwaß zu kochen haben

Aber eins hat vnß getroffen

$\mathrm{Da} \beta$ vn $\beta$ allein manglen Höffen

Den du vol, hast sie zerschlagen

Dis derfft ich niemanden klagen

$\langle 18 v\rangle$ Jetzt kan ich nichts [kochen] ohne [Häffen]

Dir weiter zu essen schaffen 
Du must vor in die stat lauffen

Vnd dorten mir newe kauffen.

Ich zwar wie ein witziger Mann

Sprach schweig still weib, ich werde schon,

Mich vmb die sochen besorgen

Wens gleich geschehen selt morgen

Dir will ich zur Noturfft bringen

Fleisch, Gwirtz vnd auch trinken

Ich wil in die stat nei lauffen

Vnd dorten Etwaß verkauffen

Vil Geld morken vnd wiederumb

Meinem Weib etwaß kauffen drumb

Hab mich bald auff den weg gemocht

Etwaß zu verkauffen Erdocht

Daß ich dardurch Gelt kent krigen

Einen in der stat betrigen

Ich hab allhir Einen Hasen

Glaubt mir er kan fein gut mausen

Den bin ich schan lang noch gangen

Entlich gar listig gefangen

Vnd ihm braff auffs Haubt getroffen

Gleich wie er schlieff auff den Offen

Diesen will ich verkauffen hir

Doch mus man gut ihn zahlen mir

Den sak wil ich nicht auffmachen

Den sie theten meiner lachen

Wan sie das thir theten sehen

Mein, ich dörfft nicht lang hir stehen

$\langle 19 r\rangle$ Wils mit sambden sack verkauffen

Vnd mit dem geld dar von lauffen

POLYPHILUS. Gott grüsse dich mein bewerlein

Waß verkauffst in den säkelein

JOKELIUS. Herr es ist nicht mehr als ein $\mathrm{Haß}$

Den ich gefangen hab in Groß

Ruen vnd schlaffen, zimlich stark

Kauffet ihm sambt mit diesen sack

POLYPHILUS. Zeig mir ihm vor dis bitt ich dich

Dan zimblich erfrewet es mich.

JOKELIUS. Ja, daß werd ich wohl nimmer thun

Wen du mir gleich vil gebest drum

Ich wil ihn lieber für mein Leib

Halten vnd geniesen mit dem Weib.

Wen ich den sack thet auff machen

Mein, du thest meiner selbst lachen.

Wen der Hoß selt dar von lauffen

Geld, du thest ihm nimmer kauffen 
Sondern mich zimlich auß zischen,

Daß selst du schon zu vor wissen,

Wer wolt mir den Hosen Holen

Oder meinen schod bezahlen

POLYPHILUS. Wie theür schetzt ihn dan sag mir

Oder waß begehrest dar für?

JOKELIUS. Herr doß wird nicht gor vil mochen

Gebet mir nur dreizehn Groschen

Nemet den sak eben darzu

Auff daß ich eüch genigen thu, $\langle 19 v\rangle$

POLYPHILUS. Da will ich dir auß der taschen

Newe geben zehen Groschen

Mehr kahn ich wahrlich nicht geben

Wen mich gleich kostet daß leben

JOKELIUS. Ey so sei, aber der ist Roth,

Wenst noch zugebest ein stuck broth

Dan ein ander ihm nicht von mir

Het bekommen so leicht glaub mir

Gott geb dir Glik daß den Hosen

Essest oder lassest mausen.

POLYPHILUS. Gott sei mit dir liebs Bewerlein

Er wird auff den Spies tantzen frey

Er wird sich anders vmbwenden

$\mathrm{Da}$ die beiner krochen werden

Doch muß ich über alles drauff

In den sack gehandleten Kauff,

Sehen vnd ihm hier betrachten

Wahrlich noch meinen erachten

Ich schätze er sey schon lengst Todt

Wer mir doß nicht ein grosser spot,

Doch weiß ich doß, daß dieses thir

Allen Leüten komb forchtsamb für

$\mathrm{Daß}$ der $\mathrm{Ha} 3$ aber darunder

So still sitzt es nimbt mich wunder.

Auwe Auwe der schelm der Dieb

$\mathrm{Da}$ ist mir gewislich nicht lieb

〈20r〉 Hat mich der Dieb nicht betrogen

Vnd so listiglich belogen

Ich narr hab kaufft wie ein blinder

Gleich so als kauffen die Kinder

Thun vnd Pflegen ohne Verstand,

Doch wie er mirs gab in die Hand

Sprach er, do hast diesen Hosen

Wen du heim kombst loß ihm Mausen

Er hot mich zwor darmohls gw[a]rnet

Vnd von der Katz treülich glernet, 
Ich aber Norr habs gar nicht gocht

Darzu weiter gar nichts betracht

Vil lieber wil ich versauffen

Daß Gelt als Hosen mehr Kauffen

In den sack stark zugebunden,

Vnd wen er gleich wehr von Lunden

Ein Exempel habt ihr an mir

Welches heit ist geschehen hir.

Also vnß arme burgers leit

Betriegen lose bawers leit.

JOKELIUS. Hui hei hug ich bins

Hei hei hei taratrara drumdrum ich bins

Ich hör noch die Geigelein

Tidli tidli tidli fidelirn

Daß seind für meinen Hosen

Meinem Weib gekauffte Haffen

$\mathrm{O}$ wie braiff werden wir kochen

Vnd vnß Hauffen speisen mochen

$\langle 20 v\rangle$ Aber ihr Herrn verzeicht mir

Ich khan nicht lenger bleiben hir

Ich bin gantz mid vnd kan nicht stehn

Ja vil weniger weiter gehn

Ihr Herrn ich bitt eüch freintlich

Nur ein kleine Weil hittet mich

$\mathrm{Da}$ mich niemant thet antasten

Ich wolt gern hir auß Rasten.

Dis thue ich eüch auch befehlen

Ich mein mir wirds niemand stehlen.

ZAMPIER. Schnarche klein wenig Jokelein

Ich wil dir alles bringen ein

Du must deine Höffen allein

zerschmetern auff kleine stüklein.

Er gab mir zwar heüt zusauffen

So vil daß ich kaum kint schnauffen

Jetzt muß ich dis ihm belohnen

Doch thue ich eüch vor vermahnen

Ihr wollet ihm daß nicht sagen

Oder mich bey ihm verklagen.

JOKELIUS. Ey du Alte, Alte wo bist

Ich mus dich nur fangen mit list

O murmel thir du bist gorstig

Vnd wie ein wilde saw Porstig

O du Alte du bist ia vol

Gantz narrisch, narrisch, vnd toll.

$\langle 21 r\rangle$ Ey ey wo bin ich steffel mein

Kom her du liebes sohnelein. 
Wo ist der sak mit den Haffen

Jo do hab ichs gleich recht gtroffen.

Ich hob eüch zum Hüttern bestelt

Ich find aber nichts auf der Welt

Weder mein Sak noch die Hoffen

Het ich daß sollen verhoffen

Ich het eüch wohl sie nicht vertraut

Weder auff eüch so vil gebawt

Jetzt wil ich gehn vnd sie suchen

In allen winklen der Kuchen

Wer diesen der sie haben wird

Sei er Glormus oder Seyffrid

Den wil ich dicht vor ableien

Vnd ihm saweres bir brewen

Aha. Bist da? du Vogel hab ich dich gefunden?

Ha, ha, ha, ich hab im daß liecht angezunden.

Ich mus doch wenig betrachten,

Wahrlich noch meinen erachten

Er thut sich gar nicht bewegen

Sie theten Hand an mich legen

Wen er Tod wer, ich mist lauffen

Kint mich schon nicht mehr erkauffen

Ich muß doch nehder zugehen

Vnd ob er noch lebe sehen

Daß ich zeitlich kint entflihen

Vnd in frembe länder zihen.

$\langle 21 v\rangle$ Auwe auwe daß Gott erbarm

Ach waß geschicht Heüt mir Armen.

Ich hab bey mir ein stüklein Wachs

Die wil ich zammen kleben stracks

Ach daß ich Kint an Galgen dich

Sehen, daß du betrogen mich

Hast, vnd gebracht in den schaden

Daß dich bald fressen die Maden.

Doch leicht gwonnen leicht verlohren

Gschicht mir Recht listigen bawren

Daß maul hat theil Gelds versoffen

Die Händ zerschlagen die Hoffen.

\section{Scena Quinta}

Der Junge Bacchus thuet seine Nochuolger freündlich ermahnen, Sie Sollen ihm fleisig nachvolgen, dann er spricht ihnen zue daß ihre freüd werde Ewig sein (derowegen volgen sie ihm alle nach[)]. Die Fasten aber wirdt von allen verlassen vnd von dem Baccho aufs aisserist vervolget.

Bacchus Præco Populus Quadragesima 
BACCHUS. Weil mir die Natur gegeben

In der Welt adelichs leben

Vnd mich erwelt hier zum König

Daß erfrewet mich nicht wenig

Mein stam ist groß vnd auch mächtig

In Geld silber vnd guld Prechtig

$\langle 22 \mathrm{r}\rangle$ Kan dieses drumb nicht verschweigen

Weil sich thut zum Höchsten Neygen

Mein Regierung vnd Regiment

$\mathrm{Zu}$ bekommen ein guttes End

Doch ehr ich waß werd Erzehlen

Wil ich dir zu vor befehlen

Doß du gehest auff die strassen

Stät Marck vnd auff alle Gassen

Dorten dein stirn lossest höhren

Daß Volg von mir kürtzlich lehren

Loß alle hir her bald kommen

Ob sie schon sein auß den frammen

$\mathrm{Daß}$ sie mein Gebott annemen

Mich für ein König erkennen

PRÆCO. Adeste Turba vocat Pater

Bacchus, parati accurrite

Properate sic mandat, jubet,

Dux noster omnibus dabit

Leges Salutares.

BACCHUS. Will kommen seit ihr sammentlich

Euch thue ich empfangen hofflich

Daß ieder auff meinen befel

Sich hat lassen befinden schnel

Eüch stelt man in ersten Orden

$\mathrm{Da}$ ihr seit gehorsamb worden

Weilen ich eüch nun hir sehe

Vnd daß mich zimblich angehe

$\langle 22 v\rangle$ Willig zu meinen Drost vnd vreit

Wen ich eüch verliß wer mir leid

Ich wil eüch Kirtzlich erkleren

Waß ich von eüch thu begeren

Deß wolt ich nun von eüch haben

Nicht Geldt oder sonst vil Gaben

Sondern daß ihr mir gehorchet

Vnd fein waß ich schoffe mochet

Von eüch andre Herren stosset

Vnd mich niemohlen verlosset

Wen ihr diesen wird noch kommen

Vil Gaben solt ihr bekommen

Noch dem werdet ihr allezeit 
Mit mir leben in Ewikeit

Essen trinken vnd Regieren

Bey tag vnd Nacht Jubilieren.

Auch kein todt wird eüch antasten

Bey mir dörfft ihr niemal fasten

Mag ieder leben wie er wil

Ist noch weit eüer letztes Zil

Vor eich werden sich Krankheiten

Förchten, vnd alle Schwacheiten

Gesund werd ihr stets sein vnd frisch

Gleich wie sind in den Wasser fisch

Nocher noch vilen Wolüsten

Wens eüch entlich thet gelisten

Werdet ihr kennen bald sterben

Vnd den Himmel so erwerben

$\langle 23 r\rangle$ Ewre Arbeit soll diese sein

Essen vnd trinken gutten Wein

Missig gehn vnd nichts arbeiten

Fröhlich sein mit gutten Leüten

Daß solt ihr wissen ammeisten

$\mathrm{Daß}$ ich eüch wil mein Hilff leisten

Wem dis gefelt der kum nur her

Darff sich vmb nichts bekümern mehr.

POPULUS. O König alle werden wir

Treilich vnd frölich volgen dir

BACCHUS. O du vngeheieres thier

Waß wilst oder suchest du hir

$\mathrm{Wa} \beta$ ist vrsach daß du allein

Dich entschleisest von dieser Gmein

Warumb kombst den nicht mir ihnen

Meiner maiestet zu dienen

Ich mein daß du auß dem Gebott

Treibest Kurtzweil, darzu ein spot

Geh hin weich ab du garstiges fich

Ich khan nicht mehr anschawen dich.

QUADRAGESIMA. O du brun aller Vnkeüscheit

Anfang aller Vnlauterkeit

Die fasten bin ich solst wissen

Dich werd ich tretten mit fissen

Ehr etliche tag verlauffen

Du wirst müssen anders schnaufen

Samb mit deiner Höllischen Rott

Do wirt eüch die Pænitentz Spot.

$\langle 23 v\rangle$ Ich hoff daß ich Triumphiren

Vnd über dich exultiren

Du wirst vnder meinen fissen

Noch deiner freid ligen missen. 
BACCHUS. Ach rechnet meiner ihr Herrn

Thut ewer Ehr vnd lob mehrn

Ermordet daß Vngehewer

Kosten wird eüch daß nicht thewer

Ihr Hoffort thut bald außreiten

Daß sich nicht berümbt bey leüten

$\mathrm{Da}$ sie auch vnß nicht verhindert

Oder vnser Glori mindert

Inuolant omnes in Quadrag[esimo]:

Nun habt ihr eins überwunden

Vnd den Feind die Händ gebunden

Er wird vnß nicht mehr nachstellen

Weder vnsere frewd fellen

Daß eintzige habt ihr gut gton

Drumb solt man eüch geben ein lohn

Daß ihr sie habt bald hingericht

Vnd außgeleichtet ohne licht

Kombt last vnß ietzund lustig sein

Bey gutten bir oder bey Wein

Kombt der Feind wird vnß nicht irren

Weder sich mit vnß verwirren

Also solt ihr stetz sein bereit

Zwingen die Wiederwertikeit.

QUADRAGESIMA. O blinde Welt o blinde leüt

Ihr vergesset Gott allbereit

$\langle 24 r\rangle$ Waß thut ihr daß den bösen Weg

Wandelt, vnd liebet Teüffels steg

Den Bacchum vnd Satan volget

Daß ewige nicht betrachtet

$\mathrm{Wa}$ ist all hir? dan Jammer thal

Angst, noth vnd Elend vberal

Dis leben wird ein kleine Zeit

Ist auch vol der Miselikeit

Vnd wers bedenkt, ein immer streit

Wens gleich wer morgen oder heit.

Heit ist der mensch schön jung vnd lang

Morgen ist er gar schwach vnd krank.

Heit ist der mensch gesund vnd stark

Morgen tod ligend in dem sarg

Drumb verlost bacchum und die Welt

Verwerfft Reichtumb vnd auch daß Geldt

Volgt Christo vnd seinem Leiden

Vnd thut auch daß böse meiden

Kein Reichen hilfft doch nicht sein Gut

Dem Jungen nicht sein stoltzer muth

Er muß von dannen bald scheiden

Dordt aber vil böses leiden 


\section{Scena Sexta}

Drey studenten thun sich erfrewen daß sie auff drey tag der schul frey sind, Erdichten ein Newes Spiel, nach diesen gehen sie den bacchum zu suchen.

Pamphilus Carinus Callidorus. E' Sales cum 2 filijs $\langle 24 \mathrm{v}\rangle$

[PAMPHILUS.] Hir her liebe Gesellen mein

Allda werden wir lustig sein

Der Bacchus ist schon gebohren

Sehr lustig vnd auserkorn

Seiner Ankunfft frei ich mich mehr

Als wan der Keiser kommt her

Dan ich der schul ganz ledig bin

Glaubt mir mein sin steht gar nicht hin

Vil lieber wolt ich außbleiben

Als dorten vil böses leiden

Dan selten ich auff sagen kan

Den magister die Lection

Doch achte ich daß vil besser sey

Wen man ledig kan sein vnd frei

In der schul thut man vnß schlagen

Vnd mit Ruten hefftig plagen

Wolt Gott ich dörffte nie gehen

In die schul oder sie sehen

Wer mir daß nicht eine sachen

Wahrlich, ich thet heimblich lachen

Aber dort kombt mein schulgesel

Gantz lustig frölich, aber schnel

Ich muß die Vrsach bald fragen

Er wirts mir wohl nicht abschlagen.

Lieber bruder sag mir waß ist

$\mathrm{Da}$ du heit so sehr lustig bist.

CARINUS. Hor ich wil dirs Recht teütsch sagen

Waß du mich thust ietzund fragen

Drumb bin ich lustig mein bruder

Dieweil ich der schul ietzunder

$\langle 25 r\rangle$ Bin ledig vnd frey gantz vnd gar

daß sag ich Pamphile für wahr

Auch mein Vatter die schul veracht

Vnd mir auß bleiben hat geschafft

Daß hab ich wahrlich gern gehört

Hat sich alsdan mein frewd gemert

Dan ich die schul auß der mossen

Gleich von Natur thue hassen

PAMPHILUS. Ja du Hertz liebstes brüderlein

Wir sein die fleisigste allein 
Auß der schul bleibest du gern

Vnd ich thus wol auch nicht sporn,

CALLIDORUS. Heist daß die schul? Vnd New gehen?

Dar schwatzen vnd müssig stehen?

Wartet ich wil auff eüch klagen

Vnd den Rekter alles sagen.

CARINUS. Italice dic mihi rogo

Fugabo verbis mox eum

PAMPHILUS. Dicor sic, Tristo catiuo Strazato

Che tu sei impicato

Che hai qua da gridare

Et con noi commandare

CARINUS. Fristu fatino strevato

Geh du sei hi implicato

Geh hey liber congregare

Vnd mit vnß nicht commendare.

Territus ecce tacet, cernis? vox faucibus illi

Hæret, nec novit quid mea verba velint

CALLIDORUS. Freilich, du hast es wohl getroffen

Dorffst wohl kein lob nicht verhoffen

$\langle 25 v\rangle$ Du meinst gelobet zu werden

$\mathrm{Da}$ du für bringst frembde Reden

Ja wohl wen du sie verstündest

Oder Etwaß wenig kindest

So weiß ich wohl daß du nichts kenst

Daß hab ich dir gesagt schon lengst

Red die Sprach die du gelernet

Vnd sey von bösen gewornet

Sondern die Haar werden krochen

Man wirds dir nicht anders machen

Aber bruder Erschröke nicht

$\mathrm{Da} ß$ ich dich hier auß mache dicht

Ich meins nicht [bös] vil lieber gut

Weils die freündschafft erfordern thut

Ich bin auch einer auß denen

Die nicht gern in schul gehen

Die hab ich nicht lengst verlossen

Dan ich bin herauß gestossen

Jetzt mog ich gehen wo ich nur wil

Auff alle Gassen zu dem spil

$\mathrm{Da}$ thut mir niemand verwehren

Ich darff weder etwaß lehren

Jetzt bin ich loß aller sochen

Waß ich nur wil kan ich mochen

Jetzt kennen wir hir sicherlich

Anfangen spielen, doch klüglich, 
Keiner wird vnß hir nicht sehen

Spielen Reden oder stehen

PAMPHILUS. Woß wil der schmarotzer haben

Sagt er nicht etwaß von Klagen

〈26r〉 Schaff ihm ab dan es wird nicht gut

Meinst nicht daß mich verdrissen tut

CARINUS. Nein er spricht gar nichts von Klagen

Oder sunst etwaß von schlagen

Sondern wil mit vnß hir spielen

Daß wir vnser muth erfillen

PAMPHILUS. Wen dem also ist so komb her

Werden vnser beysammen mehr

CARINUS. Waß für Spil wilst dan anfangen

Sog an dan es thut mich verlangen

CALLIODORUS. Dis wil ich eüch nicht verschweigen

Sondern alles treilich weisen

Doch must ihr mir gehorsamb sein

Vnd volgen meiner Red allein

PAMPHILUS. Waß meint er dan zeig mir es an

Daß ich es auch vernemmen kan

CARINUS. Er wil mochen ein newes spiel

Doch wir sollen thun waß er wil

PAMPHILUS. Mit diesem bin ich schon content

Laß ihm nur sagen daß End

CARINUS. Waß du kanst so zeig es bald an

Wie ich vermein lieget vil dran

CALLIODORUS. Ey so sei heüt liebe brüder

Weil ihr noch habt frische Glieder

$\mathrm{Zu}$ diesen spiel, welches ich eüch

Lehrnen vnd weisen werde gleich

So müsten wir vnß hir stellen

Wen wir daß spiel halten wöllen

Erstlich maultaschen außteilen

Vnd bold drauff zur erden Eilen

Nocher den Huth hinab schlagen

Vnd wie den vorigen Plagen

$\langle 26 v\rangle$ Braum braum braum müsten wir mochen

Aber gar nicht dar zu lochen

Vnd ihr also nacher zuken

Vnd sich gleich drauff nieder bucken

Bei diesen kennen wir bleiben

Vnd so lang als vnß gfelt treiben

PAMPHILUS. Daß ist fein spiel vnd gefelt mir

Ludunt Schlaget nur drein ich ich bin schon hir

$\mathrm{Nu}$ hertzliebeste brüderlein

Weil ihr habt eüch gehalten fein 
Vnd meiner gar nicht vor verschont

So mocht eüch den Weg vnd kombt

Des spiels sein wir schon alle sat

Wir werden gehen den es ist spat

Den Bacchum wollen wir suchen

In allen Wirtsheiser vnd Kuchen

Sicher kennen wir schon gehen

Der Rökter wird vnß nicht sehen

Dan er ist schon lengst bey dem Wein

Kombt wir wöllen Lehriungen sein.

Don ich hob“ noch sechs $\operatorname{Kr}[\mathrm{e}]$ ützer

Die gebe ich hin auffs bitter bir.

\section{Interludium}

Drey bettler stellen sich blind vnd sehen so gutt als andere leüt erzehlen einander ihre begangene stüklein sauffen den besten Wein speisen vnd dantzen, nach dem gehen sie auff ein gewisses Ort da sie lustig vnd guts muts sein können.

Codrus, Alluinkel, Allkirmes

CODRUS. Liebe Brüder waß wöllen wir

Anfangen oder machen hier

$\langle 27 r\rangle$ Hir wird vnß niemandt waß geben

Wen gleich kostet vnßers Leben

Ich Rath daß wir von dannen gehen

$\mathrm{E} \beta$ ist vmb sonst daß wir hir stehn

Hanßel gehe vnnd schau von forn

Ob du Kinst etwaß erfahrn

Frag in der Stadt von allen leüt

Auf welchen orth hat man heüt

Frühe auf gethan ein gutten Wein

Oder bey welchen vil leuth sein

Gehe vnnd zeig vnß diß nacher an

$\mathrm{Da} ß$ wir mit dir alle hin gahn

Wir werden deiner erwarten

Vnd noch waß zum Wein auß martern

Weillen bey vnß iezt niemand ist

Vnnd ich in euch finde kein list

Wolt ich eüch etwaß vertrawen

Wan ich nur derfft auch eüch bawen

Vnd wan ihr dißes thet verschweigen

Kurzlich wolt ich eüchs anzeigen

Diß thet eüch mit der Zeit nuzen

Vnd von villen bößen schüzen

AMBO. Diß thun wir dir hir alle beyd

Bekrefftigen mit vnßern Eid 
Daß wir niemahls auf dich sagen

Weder etwaß werden klagen

Waß du weist sags nur sicher her

Deinen Mitbrüdern alß erklör

Keiner sol das wohl erfahren

Waß wir einander erklören

Nacher werden wir eben dir

Heimliche ding vertrawen hir $\langle 27 \mathrm{v}\rangle$

CODRUS. Weillen ihr nun mir mit dem Eyd

Eüch verbunden habt allebeid

Diß verschweigen niemand klagen

Auch das ewerige sagen

So sey weillen zu dißer frist

Hir kein Frembter vor leüthen ist

Ich wil eüch alleß außlegen

Wie ich mich thue drauf begeben

$\mathrm{Daß}$ ich alle leüth betrüge

Vnd von ihnen vil erkrige

Ich bin Bettler wie ihr höret

Dieweil ihr mich gar nicht sehet

Ich zwar thu' eüch gar fein sehen

Nicht weit vor mir beide stehen

Ich muß wohl also blind leben

Wenn ich thue das Gesicht verkleben

Alle kan ich gutt erkennen

Den Weg darff mich niemand lehrnen

Wen ich aber kom in die Statt

Wen es gleich wer frühe oder Spott

Thue ich alßo mein noth klagen

Daß ich blind sei allen sagen

Auch thue ich die füß verbinden

Mit dem Hadern vorn vnd hinden

Darzu mit dem blut besprengen

Daß alle das Gesicht abwenden.

ALLWINKEL. Ha ha ha das ist ein sachen

Ich muß warlich darzu lachen

Wir sizen auf einer Zillen

Vnd mit dem Volk also Spillen

$\langle 28 \mathrm{r}\rangle$ Won vnß gefelt so sein wie blindt

parunt se Kennen zwar schon widerumb gschwindt

CODRUS. Nun können wir nider sizen

Wir werden zwar nicht sehr schwizen

Jezt können wir diße sachen

Hier in der Still treulich machen

Karten Spillen vnndt Wein sauffen

Vnd lustig eins herumb lauffen 
New Karten hab ich allhier

Die warlich wohl gefallen mir

Mit dißen werden wir Spillen

Vnd erfüllen vnßern Willen

Nacher vnß begeben zum Tanz

Vmb einen schönen grünen Kranz

BLINDSCHAW. Ein Taller sez ich iezt nur her

Wen ichs verspil ich hab schon mer

$\mathrm{E} \beta \mathrm{mu}$ auch waß beseits hirsein

Vnd auf gehebt werden zum Wein

Die fünffzig will ich drauf wagen

Doch müssen mir vnß nicht schlagen

CODRUS. Misch ich will die Karten geben

ALLWINKEL. Gib her dan daß ist mein leben

Waß wolt ihr für ein Spil geben

CODRUS. Trumpff Picket vnnd auch Trapalier

Kan ich auß bundig für vnnd für

BLINDSCHAW. Pomalich müsset ihr reden

$\mathrm{Daß}$ wir nicht verrathen werden

Ey so seit frisch vnndt auch munder

Doch nicht thut die tücher runder

$\langle 28 v\rangle$ Wir müssen Haben auff vnß acht

$\mathrm{Da}$ nicht vielleicht einer ungeacht

Herein schleiche vnndt gehe linde

Vnß beysamen Spillen finde

CODRUS. Ein gutter Rath gefallet mir

Doch daß wir vnß nicht schlagen hir

BLINDSCHAW. Gib du Codre die Karten balt

Glaubt mir es ist schon wenig kalt

ALLWINKEL. Brauchet ihr dan auch sch[n]uptawak?

CODRUS. Gib gib ich hab ihn lieb mein tag

BLINDSCHAW. Dißen thue ich vill mehr achten

Vnnd in Würtsheißern betrachten

Sein Krafft vnnd auch sein Guttigkeit

Sein Schönheit vnnd sein liebligkeit

Ohne ihn kan ich nicht gesund

Werden oder leben ein stund

$\mathrm{Da}$ ist mein tawacks bühselein

Ein flaschen oder Köstelein

Solchen tabak thu ich trinken

Vnd nacher eins darzu Springen

Kostet ihr werdet ihm wohl loben

CODRUS. Villeicht müsten wir ihm zahlen

BLINDSCHAW. Kost nur das darff man nicht zahlen

CODRUS. Warlich diß bekenn ich allein

Daß diß sey ein herlicher Wein 
ALLWINKEL. Er thut mir zimlich auch schmeken

Thue löhres geschir nur versteken

Jezt weillen wir hir allein sein

Vnd han getrunken gutten Wein

$\langle 29 r\rangle$ Wolten wir eins herumb Springen

Laß vnß deine Geigen klingen

BLINDSCHAW. Ja woll gern liebe brüder

Da bin ich ganz nicht zu wider

CODRUS. Still ih hör einen klopen dar nur drauff

AMBO. Ja frewlich

CODRUS. Glaubt mir sicher dan es ist wahr

BLINDSCHAW. Ist wahr?

CODRUS. Ja frewlich bald verdekt eüre augen

HANSEL. Liebe Vetter nicht erschreket

$\mathrm{Daß}$ ich eüch auferwecket

Bin ichs doch eüer hanßelein

Eüch wohlbekantes söhnelein

BLINDSCHAW. Du Dieb wo bist gebliben so lang

HANSEL. So seh ich wohl das ist mein dank

Ihr habt mich Ja hinauß gesand

Weil ich in der Statt bin bekant

$\mathrm{Da}$ ich eüch süche gutten Wein

Der auch zu nuzen möchte sein

Hört ich hab ein angetroffen

Den man schenckt bei dem offen

Ich hab den Wirt auch gebetten

Doch höfflich vnnd nicht geneten

Daß er eüch wöhle verzeihen

Lustig zu sein bey der Geigen

Vnd ein wohl gebuzte stuben

Ein zu gerichte in hauß truben

Auf daß ihr solt dort lustig sein

Vnd den Wein trinken dort allein

$\langle 29 v\rangle$ Er hat mir schon zugesprochen

Wens eüch gefelt Ihr solt kommen

So geet vnd eilet nur bald hin

Do kriget ihr warlich kein Gwin

BLINDSCHAW. Seht brüder wie schöne sochen

Kan vnser Hanselein mochen

Heit haben wir vil zu hoffen

In dem Wirdshauß bey dem Offen

Der Wirdt ist vnser gutter freind

Dieweil wir seine Kinder seind

Ey so last vnß bold hin gehn

CODRUS. Kombt vnd saumt eüch nicht

ALLWINKEL. Hört, wortets wo seit ihr dan. 


\section{Actus Secundus De Baccho Convinante}

Der Bacchus last einkauffen alle nothwendige sochen für die Göst, doch heimblich thut er seinen Dienern daß selbe anzustellen befehlen. Der Zampier aber daß er des Herrn Gebott nicht herauß blodere, thut er da $\beta$ ienige in die Erden vergraben, dan sie am besten still s[ch]weigen kan, aber es geschicht ihm Widerspil.

\section{Scena Prima}

\section{Bacchus Populus Zampier E Famuli}

BACCHUS. Weillen wir nun sein zusamen

Liebe herrn hie her komen

Hab ich nicht betrüben wöllen

Oder in traurikeit stellen

Sondern machen ein gutten Mutth

Der eüch heündt erlustigen thut

Erstlich muß ich eüch Dank sagen

〈30r〉 Kein nachleßigkeit nicht klagen

Fleissig habt ihr mir gedienet

Auch wie merklich herzlich geliebet

Daß vergelten bin ich bereit

Euch auf zu warten allezeit

Zahlen will ich doch nicht mit Gelt

Dem manicher gar sehr nachstelt

Weder mit silber oder Golt

Durch welches sucht man vil huldt

Sondern mit Essen vnd trinken

Kurzweil Treibung und mit Springen

Der mir nachfolgen wird trewlich

Vnd mich ehren vor möniglich

Auch meinen Gebott nachgehen

Den will ich fleissig versehen

Der dißen allen nachkommet

Wird er von mir reich belohnet

Den Todt wird er nicht gedenken

Auch wird ihm kein schwachheit krenken

Alle Krankheit werden weichen

Nicht zu vnß sondern zum reichen

Ihr aber alle liebste mein

Werd bey mir alle lustig sein

SOCII. Bacche thust vnß vill zusagen

Vnd lustiges heünd vortragen

$\langle 30 v\rangle$ Gern wolten wir auch hören

Wen du thest dein reich erklören!

BACCHUS. Morgen solt ihr daß erfahrn

Meine Herren auß erkorn

Mein reich müst ihr alle sehen 
So vil ewer allhier stehen

Doch zu vor muß man eüch Speisen

Eher ihr von vnß werdet Reißen

Lustig werden wir alle sein

Bey meinen gutten alten Wein

Ein einziges begehr ich von eüch

Wen ihr abzihn welt iezt gleich

Dan ich wolt mit meinen leüthen

Etwaß heündiges bereiten

Eüch hab ich waß vor zu bringen

Den auf mich vill Göste tringen

$\mathrm{Da}$ ihr heimblich das auß richtet

Vnd etwaß newes dichtet

Die Göst fein zu erlustigen

Aber mit sachen listigen

Daß alle geniegen haben

Vnd auff vnß sich nie beklagen

Doch müst ihr die Sach verschw[e]igen

Vndt keinem menschen anzeigen.

Daß ich dem Volk ein Gasterey

Will anrichten vnndt fresserey.

〈31r〉 Gehe du auf dem Plaz vnnd kauff ein

Doch von anfang dem besten Wein

Vernaczer Estereichischer

Ducaischen vnnd vngrischen

Verschaffe auch ein guttes Bir

So gutt alß man kan finden hir

Kauff auch hiener vnndt Capauner

Rebhindel vnndt auch fasannen

Anten genß konstu auch suchen

Vnd erfillen vnßere Kuchen

Deß Confects thue nicht vergessen

Weil ich ihm thue gern Essen

SYRUS. Herr auß waß werden sie sauffen

Weillen ihr kein Gschir welt kauffen

Vill habt ihr nöchsten zerschlagen

$\mathrm{Da}$ wolt ich eüch lengst schon sagen

Daß ihr andere thet schaffen

Bey dem Dienst muß man nicht schlaffen

BACCHUS. Gehe bald vnd thue alß einkauffen

Zu Eßen vnd auch zu sauffen

Dan sie werden dir beyneben

In meinem nahmen alles geben

Doch am meisten ich befehle

Vnd mit dir also bestelle

$\mathrm{Daß}$ du auch den Spanischen wein 
Suchest, den ich ihm trink allein

In summa schaw daß gasterey

Allen mangel vnd Klag sey frew

$\langle 31 v\rangle$ Wan du dißen wirst nachkomen

Großen lohn wirstu bekomen

ZAMPIER. Herr wo werde ich damahls stecken?

BACCHUS. Schweig du wirst die taller lecken

$\mathrm{Da}$ werd ihr thun wie ich hoffe

Vnd euch iezunder hin schaffe

Secht zu laß keinen nichts mangeln

Gebt auch achtung auf die Kantlen

Daß sie nicht lehr auf dem tisch stehen

Darauff []ir am meisten sehen

Must, vnd fleissig achtung geben

So lieb alß euch ist das leben

Den Mußicanten müst ihr auch

Weil daß ihrer sey alter brauch

Esen vnd trinken gebe sat

Dan sie das lieben frühe vnd Spatt

Ihnen sol man billich geben

Die weil sie von der Kunst leben

Auch alle leith erlustigen

Mit ihren schönnen musigen

Jezt laß ich auch darumb sorgen

Daß ihr dem nachkomet morgen

Kombt ich muß eüch vor waß fragen

Diß darfft ihr niemand sagen

ZAMPIER. Gehet folget ihr herrn Bacchum

Mein herr wil morgen gasterey

Machen vnd grosse fresserey

Daß darff ich niemanden sagen

Wen mich gleich einer thet fragen

〈32r $\rangle$ Sprach ihr werd belohnet werden

Wen ich nichts dar von werd reden

Ich aber daß ichs verschweige

Vnd habe nacher kein Klage

Dan ich glaubt mir nichts schweigen kan

Sag alles gleich ein Jeden mann

So hab och diß bey mir bestelt

Dan es mir zimlich wohlgefelt

$\mathrm{Daß}$ ich dißes Gebott werde

Vertrawen allein der erde

Sie kan am besten still schweigen

$\mathrm{Zu}$ ihr muß ich mich gleich neigen

Vnßer herr Bacchus morgen frühe

Daß sol keiner wissen allß du 
Anrichten wird conuinium

Schweig stil ist mein consilium

\section{Scena secunda}

Drey blinde suchen den Bacchum, weliche ihr Jung thut außlachen: Die blinden Rihmen ihre Reichtumb der Zampier aber thut ihnen auffmerken vnd sie klüglich berauben vertauschend einen den Mantel, den andern den Huet, den dritten die schuch, in welichen daß Geld vernehet ist Codrus Aluinkel Allkirmes $\mathcal{E}$ Hansel Ẽ Zampier stinckfisselius Altseccius

Vox Zampetri superior, dicetur sub theatro. tamen cantus procedit quo dicto audietur hac vox inferius

CODRUS. Hört libe brüder eine stim

Die fordert vnß von dannen hin

Wo wird den sein die Gosterey

Oder des Bacchi fresserey

Vil haben wir dar von gehört

Jetzt hat sich aber hir gemert

$\langle 32 v\rangle$ Lost vnß gehen wir werden fragen

Die Leüth werden vnß schon sagen

Villeicht bey dieser saufferey

Lossen vn $\beta$ auch der irden frey

STINKFISL. Am meisten sein wir her gangen

daß wir kinnen waß erlangen

ALTSECIUS. Hansel, Hansel kom her wo bist

Du Dieb ist in dir grosse list

Gib mir dein Hand wir werden gehen

Wir kennen nicht hier lenger stehen

HANSEL. Ihr thut mich ia zimblich plagen

Aha ihr wolt mich gern schlagen

ALTSECIUS. Komb her ich thue dir nichts, dan wir

Kennen nicht lenger bleiben hir

Wo bist dan?

HANSEL. Auwe her auff ich bitte dich

Alzeit fromb wirst befinden mich

ALTSECIUS. O Scherm worumb bist so böß

Ich muß dir einmohl geben stes

Geher wo bist?

HANSEL. Ich ge nicht du thest mich schlagen

Vnd vil herter alß vor Plagen

Ja wen du mir test zusagen

Daß du mich nicht mehr wirst schlagen

ALTSECIUS. Ney kom nur her ich thue dir nichts

Ey du Dieb worumb kombst nicht

Wen ich dich Ruffe 
HANSEL. So kombt aber doch botz leide

Loß sie worten alle beyde

$\langle 33 r\rangle$ Es ist ein tieffe Gruben hir

Vber weliche ihr grosse mie

Haben werdet, dan zum schreiten

Wird sie weit sein auff die seiten

Spring, die Gruben ist zimlich breit

Ich bin schon hir auff dieser seit.

ALTSECIUS. Ach we mich alten blinden Mann

Der nichts in der Weld sehen kan,

Ach du scherm du loser Dieb

Wan du ghenckt werst wer es mir lieb

Waß hast mir Alten zugericht

Der in der Welt gsicht gar kein licht

$\mathrm{O}$ daß dich die Raben finden

Vnd der Henker heüt außschinden

Gott geb daß du wirst gehenket

Vnd daß dirs Gott nimmer schenket

Ich hoff Gott wird mir Hilff Reichen

Vnd von dir gantz vnd gar weichen

Ach wie hob ich auß der mossen

An die Mawer angestoßen

Auwe bluts doch manich

CODRUS. Hansel der Alte thut klagen

Ich mein er thut dich auch schlagen

HANSEL. Ich hab gsogt er sol hin schreiten

Über ein Grub auff die seiten

Er ist aber hinein gfallen

Drumb hat er mich schlagen wollen

CODRUS. Kom loß vn $\beta$ auch hin bald hinken

Villeicht werd ich besser springen $\langle 33 \mathrm{v}\rangle$

HANSEL. Kom doch gib Achtung auff dich

Spring, Hahahaha.

Ey du kanst wahrlich gut springen

Vnd auß lehren gschiren trinken

So wo hast glernet diese Weiß

$\mathrm{Zu}$ dantzen vber mich so leiß

CODRUS. O we wie hab ich mir we gton

Ich armer vnd Elender Mann

O du Dieb daß du verendest

Oder der Hunden speiß werdest

$\mathrm{O}$ daß du gehling hin sterbest

Vnd als wie ein Hund hin verderbest

Du darffst fuppen mich alten Monn

Der dir alles Gutts hot gethon 
HANSEL. Noch eüch frag ich nichts ich bin frey

Mehr gold hab ich als ihr all drey.

CODRUS. Bist dar du leichtfertiger scherm?

STINKFISL. Auwe auwe wer schlaget mich?

CODRUS. Ach bist du daß stinkfissel mein?

STINKFISL. Ich bins freilich liebs Coterlein

Worumb thut ihr mich traktiren

Vnd allso beyde hort schmiren

Ich hob eüch ia gar nichts gesagt

Weder vmb etwaß eüch geblagt

AMBO. Verzeig vnß liebstes brüderlein

$\mathrm{Da}$ wir über dich kommen sein

Warlich ist vnß dieses nicht lieb

Daß unß betrogen hat der Dieb

Den Jungen haben wir wöllen

Mit dem schlagen vberfollen

Schweig schweig nur liebes brüderlein

Wir werden schon vnß bey den Wein

$\langle 34 r\rangle$ Vergleichen vnd gutte freindt sein

STINKFISL. Dis Kint ich eüch leicht verzeigen

Wan ihr mir waß wellet leigen

Heüt zu Abent auff gutten Wein

$\mathrm{Da} 3$ wir wiedrumb gutte freind sein

ALTSECIUS. Daß kan leichtlich heit geschehen

Ehr wir werden noch Hauß gehen

Doch wahrlich müssen wir Reden

$\mathrm{Da} \beta$ wir nicht vertriben werden

STINKFISL. Wen wir aber zum Wein kommen

So als wir hir stehn bey sammen

Vnd kein Geld mit vnß nicht bringen

Schlecht werden wir glaubt mir trinken

CODRUS. Wen ich werwechslen thet wolt ich

Gleich wol etwaß zahlen für dich

Ich kleines Gelds hab kein Haller

Wil auch nicht han gantzen toller

ALTSECIUS. Schweig, nicht Red so laut dis all hir

Wer schlim mit eüch vnnd auch mit mir

STINKFISL. Hansel Hansel, er ist ia nicht da.

ALTSECIUS. Wer schlagt mich?

STINKFISL. Ich suche ob iemand hir stehe?

Jetzt sein wir hir fein hipsch allein

Ist hir weder mein Hanselein

Nun kennen wir Reden keklich

Mit ein ander aber freindlich

Von vnseren thun vnd leben

Vnd wie vnß Gott thut als geben 
Ich hab schon lengst wöllen wagen

Vnd eüch heimblich beiden sagen

Von meinigen vernehten Geld

Eüch verborgen vnd auch der Welt

$\langle 34 v\rangle$ Gott lob ich hob schon beysammen

Hundert Dukaten bekommen

Die alle hob ich allbereit

In meinen mantel eingenaat

Wen ihr mir nicht wöllet glauben

Greiffet, ich thu eüch erlauben

CODRUS. Do sein sie wohl nicht Recht verwort

Leichtlich kent man sie stehlen dort

STINKFISL. Glaubt mir sicherlich mit nichten

Thu ich mich vmb daß Geld firchten

Dan mein leib beschitzt daß selbe

$\mathrm{Da}$ es villeicht nicht verderbe

Auff halben mantel ich lige

Vnd also die dieb betrige

ALTSECIUS. Vil besser hab ich meinige

Werwahret als du die deinige

Meine Dukaten hab ich in schuhen

AMBO. Wu wu sagst du?

ALTSECIUS. In schuhen seit ihr dan so taub

Drumb hab ich sie meinen fissen

Am meisten befehlen missen

Dan wen selt auff mich ein mohl forcht

Kommen es sey hir oder dort

Daß sie daß Geld dar von trigen

Vnd allen vnglik entfligen.

CODRUS. Hest sollen besser verwohren

Dan sie bold werden verlohren

Wen den die schuch sein zerrissen

Die Taller auß fallen müssen

Ich hab die Dukaten dem Haubt

Besser als ihr beide vertrawt

$\mathrm{Da} \beta$ Haubt ist daß verstandigste

Vnd zum beschitzen witzigste

〈35r $\rangle$ Der Hut ist meine schatz Kammer

Vnd daß Haubt ist driber schoffner

Ohne Hut kans Haubt nicht bleiben

Vnd anstat des bets wol reiben

Der Hut ist nicht sein toch allein

Sondern bisweil ein Haubtkislein

Finff Hundert hab ich biß hir her

Versamlet Dukaten, nicht mehr

Sechs Gulden hab ich noch driber 
Die halt ich zum Abent brüder

Sechs hab ich nechsten versoffen

Auff andere kan ich hoffen

$\mathrm{Zu}$ den Offen werden wir gehn

Es ist nicht gut lang da hir stehn

Bey ihm kennen vnß alle leüt

Dan sie zu dienen vnß sein bereit

Die Musica ist auch nicht weit

Dan sie bey ihm bleibt allezeit

Ein Gulden gab ich ihr nechsten

Allein, dan war schon zum letzten

Heüt muß man ieder zwey Gulden

Den frommen spieleiten hulden.

Doch ich ermahne eüch schweigt still

Vnd von der sach redet nicht vil

$\mathrm{Da}$ nicht villeicht einer keme

Vnd vnß diese Reichtumb neme

Vnd vnß darzu gut stes gebe

Daß gschah so wohr als ich lebe

ZAMPIER. Oho daß wird ein wildpret sein

Für mich vnd meine Söhnelein

Gott griß eüch arme blinde leüt

Wie kombts daß ihr so trawig seit

$\langle 35 v\rangle \mathrm{Wa}$ thut ihr hir allein mochen

Vnd vnder einander sprohen

OMNES. Gott da[n]k eüch o Herr tausent mohl

$\mathrm{Da} ß$ ihr vnß habt gegrüsset all,

Mir warten hir ein Charitet

Vnd gutter leüt benignitet.

ZAMPIER. Hat eüch dan niemand nichts geben

ALTSECIUS. Nein Her hat vnß niemand geben

ZAMPIER. Nu so wortet ein klein weil

Ich will hinlauffen in der Eyl

Vnd euch ein Allmoßen bringen

Eß wird euch heund noch gutt glingen

Da bring ich eüch iezt allbereit

Allmoßen ihr betrübte leüth

dir will ich erstlich ein gutten

Mantel geben für den alten

STINKFISL. Ach Herr vmb Gottes willen bit ich

Bey meinen Alten lasset mich

In den Newen ich armer Man

Möcht bekommen einen schlechten lohn

ZAMPIER. Mein Alter darffst dich nicht förchten

Der Mantel ist zwar mit nüchtern

So schön alß du dir ihm einbildest 
Oder ihm selber haben wilst

Ich kan dich nicht anschawen mehr

Gib nur den Alten Mantel her

Dein Hut ist auch zimlich zerstukt

Vnd mit villen lappen geflikt

Ein newen hast nimb hin darfür

Dan nichts altes gefahlet mir

〈36r $\rangle$ Nimb vnnd bitt fleissig Gott für mich

Daß einzige bitte ich dich

CODRUS. Nicht nembt mir ihn ich bitte eüch

Für mich alten schickt er sich gleich

Dan ich halt ihn derowegen

Daß durch ihn noch nicht thut regen

ZAMPIER. Etwaß opfern ist große sündt

Wen daß selbe nicht geschicht geschwindt

Nimb waß ich dir thue iezt geben

Du must nicht sein so verwegen

Dir will ich auch Paar schuch schenken

Deine Armut thut mich krenken

ALTSECIUS. Ich bitte eüch Herr vmb gottes will

Nicht blaget mich mit neüem vill

Dan meine füß sein ganz verwund

Auch vmb vnd vmb gar vngesund

ZAMPIER. In dißen fahl bin ich listig

Dan ich hab kaufft die schuch wizig

Ich hab weiche schuch genomen

Weil ich von dir daß vernomen

Setz dich nider vnd gib die her

Alte mag ich nicht sehen mehr

Jetzt känt ihr fort gehen mit Gott

Sogt kein Nichts daß ist mein Gbott

Wegen der Gab muß man sich nicht

Lassen vil sehen bey dem Licht

Ich wolt nicht daß mich leüth kennen

Oder bey den Nahmen nennen

Fort mit den Almosen zum Wein. 〈36v

ALTSECIUS. Schlim haben wir außgekochen

Waß werden wir weiter mochen

O Maul maul vil hast versoffen,

Wer ich lieber dar von gloffen,

Hest stil geschwigen ietzt kinst mochen

Vnd mit samleten Geld schoffen

Jetzt wirst müssen ein Weil fasten

Vnd mit den andern außrasten

Jetzt kanst du wiederumb fort gehen

Vnd vmb anders Geld vmbsehen. 
Es ist vmb sonst sich beklagen

Vnd die Armut noch mer blagen

Kein Jud wird nichts mehr leigen drauff

Es ist schon geschehen der Kauff

Es ist zwor war daß ich die schuch

Hob bekommen die hon kein Luch

Hob sie theier zahlen müssen

Daß wird mich mein tag verdriessen

Tewer sein sie ich muß sehen

$\mathrm{Daß}$ nicht täglich darff drin gehen.

Ich hob zwor noch mer Geld bey mir

Dis thut zwor niemand wechslen hir

Dis Geldt thut sich zimblich halten

In Hosen zwischen den falden.

Thut auch herumb braff spatziren

Vnd meine Kleider schön ziren

Mit diesen Wil ich fort gehen

Ich derff nicht lenger hir stehen

\section{$\langle 37 r\rangle$ Scena Tertia}

Der Diener des Bacchi thut alle loden auff die Mahlzeit Er zehlt vnderschidliche speisen, vnd Getränkh. Der Zampier thut ein Speis von des Herrn taffel stehlen vnd seinen Söhnen ein Mahlzeit bereiten, In diesem aber als sie am besten anfangen zu essen kombt einer auß dem Wirts Hauß dicht abgepleierter, welcher sie vertreibt vnd sich des vngliks weliches ihm in dem wirtshauß Ist wiederfahren, beklaget.

Dromo Zampier 2 filij. Demanetus.

DROMO. Allen Herrn hir iedes stands

Wirden dignitet vnd auch Lands

Mein Herr seine demütige

Dinst last sagen, vnd Embsige

Sie wolten sich nicht lang seumen

Sondern zur Gosterey kommen

Es ist schon alles zugericht

$\mathrm{Daß}$ ist mein gewisser bericht

Die Tisch gedeckt allß auff gebutzt

Waß zum trinken vnd Essen nutzt

Die Musicanten auch dorten

Auff eüch Herrn fleisig warten

Herbauken sein schon auch bereit

Die Trompeten darvon nicht weit

Waß anbelonget die speisen

Wird man Erst dorten beweisen

Von trank vnd auch von vilen Wein

Wird vberfleissig dorten sein 
Kombt daß wird ihr alles sehen

Ich derff hir nicht lenger stehen. $\langle 37 \mathrm{v}\rangle$

ZAMPIER. Jo, wohl daß sein alls faule fisch

Geh s[ch]watzer auff warten zum tisch

Der Herr fangt an schon zu essen

Hat deiner warlich vergessen

Man solt dich vmb den todt schiken

Er du kwemst mecht man Erstiken

Kans den nicht mit wenig worten

Verrichten In allen Ertern

Dis daß der Herr hat befohlen

Die Gäst bolder abzuholen.

Stehst den noch hier du Grobian

Man muß dir kauffen stolprian,

Hörst nicht daß der Herr schon isset

Wo du werest gar nichts wisset

DROMO. O Zampier wie thust du liegen

Vnd mich ietzunder betrigen

Loß mich gehn daß ich kan lauffen

Bier hab ich nichts zu verkauffen

ZAMPIER. Lauff lauff do wirst schon bekommen

Für dein gswindes wiederkommen

I Jo, wer ich so Reich als mein Bacchus

Oder wie zu Rom der Grachus

Wahrlich ich thet eüch Prandium

Oder Ein guts Conuivium

Bold anstellen vnd Richten hir

Dis wer zu nutz Eüch vnd auch mir

Aber nichts ist in der Kuchen

Wil ich waß han muß ichs suchen

$\langle 38 \mathrm{r}\rangle$ Doch ich muß mich drumb besorgen

Vnd selt ich stes haben morgen

Ich wil den Herrn auff warten

Vnd erschnappen Etwaß dorten

Ein taller wil ich in der Hand

Halten, wie sich gbirt meinem stand.

Wird mein Taller waß antreffen.

Glaub ich wils wohl nicht weg werffen

Sondern daß selbe nemen straks

Vnd wens gleich wer ein gantzer Ochs

Daß wil ich bold noch Hauß tragen

Wortets wenig ich wils wagen

Eüch vnd meine Kinder speisen

Höfflikeit allen beweisen

Jetzt gleich wil ich wiedrumb kommen

Wan ich Etwaß kent bekommen 
Die Partiten kan ich gar wohl

Vnd wen ich gleich schon werden vol.

Ey so kombt ihr Herren hir her

$\mathrm{Da}$ vnser beysammen sein mer

$\mathrm{Daß}$ hob ich schon zuvor gewüst

$\mathrm{Daß}$ ich waß krige mit der list.

Weil die Herrn nicht sollen gehn

Waß sollen wir missig dar stehn

Kombt derowegen söhnelein

Mir allerliebste Kindelein

Esset vnd seit lustig darbey

$\mathrm{Da} \beta$ thu ich eüch erlauben frey

FILII ZAMPETRI. Vatter die speiß wer vnß wol sis

Wan wir nur hir hetten ein Tisch

Es wer Vatter wahrlich besser

Wen wir hetten Tisch vnd Messer $\langle 38 \mathrm{v}\rangle$

ZAMPIR. Wartets ihr liebe Kindelein

Zum Tisch machet ihr Ruken mein

darauff setzet ihr schisselein

Vnd isset beide darauß fein

Comedunt. Hos fugat ebrius.

DAMÆNETUS.

Heu mihi vas machen cum quatuor schlagen in unum

Priglibus, ah multum zerschligen brachia drinne.

Non credam post hac cum solus poc[u]la levabo

In craemis dan mich erschreket büchene fustis.

In primis fuimus sammentlich gutte Sodales

Et socij simul ein ander bona verba gabantes.

Ebria sed posthac cum esset mea turba falerno

Cum Baccho Protwurst cognata stirpeque Blutwurst

Pro multis uortis kwamen sie ad uerbera tandem,

Pratlius haud unam demisit in Ilia Kleislam

Iamque calescebat verstendigs utque disertus

Herr Protwurst stolcis iactabat pectora linguis

Jetzt Latium wirkent, ietzt Boiam ex tempore Ruppfend

Jetzt Græcam trukend dan Iberum gutture drohlend

Auch Teütsch kum Rauß kum stechen Hawen plurima spargens

Potz hader Potz schantzen beiß mir von Cuspide spitzen

Insuper ut breichlich læto per compita schreio

Spargebat patulis iuchzando iubila fenstris

Ipsa domus iam kleina fuit peruadit ad omnem

Abdomen winkluum miscetque furentia zornig

Jurgia: nulla bonum bringt dar von Klaslia wortum

Interea von ofen furiali percita ab æstu

Cum brotwurst mox ante fores excitu cucurrit

Blutwurst, innocuum hic noscens esse duellum

Mox longum 


\section{Kommentar}

\section{Übersetzungen, Wort- und Sacherklärungen}

2r Synopsis ... Febr.] (lat.) Synopse bzw. Zusammenfassung des gesamten Spiels von des Bacchus Geburt, Leben, Ringen mit der Fastenzeit, Tod und schließlich ewiger Verdammnis, in Szene gesetzt von der studierenden Jugend des Nikolsburger Kollegs bei den Armen der Mutter Gottes von den Frommen Schulen [= Piaristen] im Jahr 1654 seit der Wiederherstellung des Heils, am 15. Februar Prologus ... liberant] (lat.) Prolog begrüßt das Publikum freundlich und erzählt, was das Spiel beinhaltet oder was in selbigem geschehen wird, wird aber von einem fremden Gast daran gehindert, mehr zu sagen. Dadurch beleidigt versucht Prolog jenen aus dem Theater zu vertreiben. Allerdings eilen die Söhne des Gasts wie besprochen dem Vater zur Hilfe und befreien den Vater, den fliehenden Prolog verprügelnd.

2v Actus Primus ... Navitate] (lat.) Erster Akt: Von der Geburt des Bacchus Scena Prima ... trahant.] (lat.) Erste Szene. Auf Befehl Luzifers kommen die Dämonen zu einer Beratung zusammen, auf welche Weise sie die Menschen in die Tiefen der Hölle bringen könnten. Nach langem Ratschlagen beschließen sie, alle in veränderter Gestalt auf die Welt zu gehen, um dort die Sterblichen durch Bacchus vom enthaltsamen Leben zur Gefräßigkeit, Trunkenheit und Lasterhaftigkeit und schließlich in die Unterwelt zu ziehen. Scena Secunda ... Hariolo.] (lat.) Zweite Szene. Semele, die Mutter des Bacchus, erzählt ihren Traum, den zwei Zigeunerinnen deuten. Zampier stiehlt einer Zigeunerin arglistig den Geldbeutel. Scena Tertia ... natalia.] (lat.) Dritte Szene. Ein Bote verkündet, dass Bacchus geboren sei, und ermahnt alle, die Kehlen für die Feier seiner Geburt bereit zu halten. Scena Quarta ... confringit.] (lat.) Vierte Szene. Um Geld für die Feierlichkeiten zu Ehren des Bacchus aufzutreiben, heckt ein Bauer die List aus, einem Bürger eine in einem Sack eingesperrte Katze anstelle eines Hasen zu verkaufen. Für den Erlös kauft er Wein und Töpfe, die er betrunken einschlafend verliert und dann (weil es Zampier so arrangiert) mit den eigenen Händen zerschlägt.

3r Scena Quinta ... affligitur.] (lat.) Fünfte Szene. Der noch jugendliche Bacchus fordert die Seinen auf, ihm beständig zu dienen, so werde ihre Gastgemeinschaft zukünftig ewig währen. Die Fastenzeit aber wird von allen verlassen und von Bacchus und seinen Dienern übel zugerichtet. Scena Sexta ... quæsitum.] (lat.) Sechste Szene. Drei Studenten freuen sich über die dreitägigen Faschingsferien und denken sich zur Unterhaltung ein neues Spiel aus; nach Ende des Spiels setzen sie ihre Suche nach Bacchus fort. Interludium ... concedunt.] (lat.) Zwischenspiel. Drei Bettler stellen sich blind, obwohl sie so gut wie andere Menschen sehen. Sie erzählen einander ihre Techniken und Machenschaften, mit denen sie die anderen an der Nase herumführen. Sie spielen, trinken ausgezeichneten Wein, tanzen und gehen schließlich in eine Kneipe. Actus Secundus ... vita.] (lat.) Zweiter Akt: Vom Leben des Bacchus

3r-3v Scena Prima ... evenit.] (lat.) Erste Szene. Bacchus kümmert sich darum, dass alles Notwendige für das gut vorzubereitende Fest mit seinen Gästen eingekauft wird, doch befiehlt er seinen Dienern, es heimlich anzustellen. Zampier aber, damit er das Gebot seines Herrn nicht ausplappere, verscharrt es in der Erde, da diese es verlässlich verwahrt; doch kommt es anders. 
3v Scena Secunda ... sunt.] (lat.) Zweite Szene. Drei blinde Bettler suchen Bacchus und werden von ihrem Leitjungen gefoppt. Sie prahlen mit ihren Reichtümern, weil sie sich allein glauben. In Wirklichkeit aber belauscht sie Zampier und bestiehlt sie raffiniert, indem er deren Mantel, Hut und Schuhe, in denen Dukaten eingenäht sind, austauscht. Scena Tertia ... accusat.] (lat.) Dritte Szene. Ein Diener des Bacchus lädt alle zum Fest, das Bacchus prachtvoll vorbereitet hat. Er zählt die Speisen und Getränke unterschiedlichster Art auf. Zampier stiehlt einen Bissen vom Tisch seines Gebieters und bereitet seinen Söhnen eine Mahlzeit. Als sie beim Essen sind, kommt ein aus der Kneipe geworfener Säufer, der sein übles Geschick beklagt. Scena Quarta ... imposituram.] (lat.) Vierte Szene. Die vertriebenen Fasten, Nüchternheit und Keuschheit beklagen sich, der Tod tröstet sie und verspricht, dass er diesem Exil ein Ende bereiten wird.

4r Scena Quinta ... fatalem.] (lat.) Fünfte Szene. Bacchus tritt nach dem vollendeten Gastmahl mit seinen Gästen auf, um diese wieder zu erfrischen. Zunächst sorgt er dafür, dass Zampier und seine Söhne einen Tanz beginnen, schließlich gibt er sich selbst voll Lust mit einer seines Gefolges den Tanzbewegungen hin; allerdings kann niemand mit den klingenden Akkorden aufhören bis alle erschöpft zur Erde sinken und Bacchus mit ihnen; wovon er eine verhängnisvolle Krankheit bekommt. Scena Sexta ... fugat.] (lat.) Sechste Szene. Vier Pan-Priester aus dem Gefolge des Bacchus tanzen ausgelassen mit dem Tod, den sie für eine Jungfrau hielten; dieser selbst verjagt die völlig Verschreckten. Interludium ... saltu.] (lat.) Sechs schon volle Bauern beraten sich, wie man den mit Speisen vollgestopften Magen für das Abendessen erleichtern könne, damit sie wieder essen können. Sie einigen sich, es mit Tanzen zu probieren. Actus Tertius ... morte.] (lat.) Dritter Akt: Vom Tod des Bacchus Scena Prima ... inferno.] (lat.) Erste Szene. Die Teufel laufen zusammen und freuen sich, dass sie die Sache gut angegangen sind; sie ermuntern sich gegenseitig, Bacchus mit einem Gastmahl und einem guten Bad in der Hölle aufzunehmen.

4v Scena Secunda ... invitant.] (lat.) Zweite Szene. Ein Arzt kommt aus einer entlegenen Provinz. Zampier wird mit Medikamenten des Arztes geheilt. Die Lehrlinge laden den Arzt zum kranken Bacchus ein. Scena Tertia ... sepelit.] (lat.) Dritte Szene. Der Arzt bemüht sich, den schon mit dem Tod ringenden Bacchus zu heilen. Bacchus stirbt. Sein Gefolge betrauert den Dahingeschiedenen; es öffnet den Bauch, dann verzehrt es die Eingeweide und begräbt ihn schließlich. Scena Quarta ... agere.] (lat.) Vierte Szene. Fasten, Nüchternheit und Keuschheit freuen sich, dass Bacchus, der Verursacher alles Bösen, aus dem Leben geschieden ist. Scena Ultima ... rident.] (lat.) Letzte Szene. Die Seele des verdammten Bacchus klagt in der Hölle und schmäht alle; Die vier Elemente Wasser, Erde, Feuer, Luft klagen denselben an und fordern Gerechtigkeit; Die Dämonen selbst schlagen den Verdammten nieder und lachen. Chorus ... pollicentur.] (lat.) Chor. Verkündet, dass alles nichtig sei und jene, die es mit der Welt und Bacchus halten, ein sehr schlechtes Ende nehmen werden. Epilogus ... Finis.] (lat.) Epilog. Ermuntert das Publikum, dass sie Bacchus, der ein schlimmes Ende fand, fliehen; sagt Dank für das dem wohlwollenden Publikum Präsentierte; entschuldigt die Fehler und verabschiedet sich zuletzt. Ende

6r duo filij zampetri] (lat.) zwei Söhne des Zampier

6v dorstenson] Lennart Torstensson (1603-1651), gefürchteter schwedischer Feldherr im Dreißigjährigen Krieg, brach 1644 mit seiner Armee in Böhmen ein und zog brandschatzend Richtung Wien; Nikolsburg wurde im April 1645 eingenommen und geplündert, die 
Piaristen wurden vertrieben, 10.000 Bände und 200 Handschriften aus der Bibliothek des Kardinals Franz von Dietrichstein nach Uppsala gebracht

7r Welisch] Italienisch Bere vnndt mongiare] (ital.) trinken und essen (mangiare) vorare] (lat.) gierig fressen schei] scheue nein] hinein

7v Ingenium] Verstand, Geist Judicium] Urteilskraft, Geschmack

8v Adeste .... Jubet] (lat.) Kommt, Fürsten der Unterwelt, Belzebub und jede Kraft und Macht des Tartarus, schnell schnell, Lucifer, euer Gebieter, befiehlt Rewers] Antwort, Verpflichtung Obschon ihr werdt] auch wenn ihr wäret Kuchen] Küche Nutant capitibus] (lat.) Nicken mit den Köpfen

10r Adhortirt] ermuntert kwem] käme (zu ahdt. queman)

11r confirmiren] bestärken auß striken müllich mälken] aus Stricken Milch melken: häufige Unterstellung in Hexenprozessen erwirken] erwürgen, umbringen tentiren] versuchen

12r kind] könnte content] zufrieden Mankement] (franz. manquement) Vergehen, Pflichtverletzung

12v Semele Mutter Bacchi] Semele: Tochter der Göttin der Harmonie und des Königs von Theben, Kadmos; Zeus erscheint ihr zunächst als Sterblicher und zeugt Dionysos (Bakchos), dann auf ihre Bitte hin in göttlichem Glanz, der sie tötet; die Leibesfrucht wird jedoch gerettet und wächst im Oberschenkel des Vaters heran

14v Carbunclen] Karfunkel(stein), veraltet für roter Edelstein (Granat, Rubin etc.)

16v-17r NUNCIUS ... pocula] (lat./dt.) Bote: Als Bote aus fremden Ländern bin ich - glaubt mir - hierher geschickt worden, versehen mit verschiedenen frohen Nachrichten und Schreiben. Freut euch, ihr Volk, freut euch, meine Kameradenschar und ihr Studentenburschen, weil die Feiertage des Sorgenbrechers [= Bacchus Lyaeus] schon kommen, die euch längst schon bekannten Brateln (Braten). Deshalb macht heute eure Bäuche bereit und reinigt die Mäuler, die Kehlen mitsamt den Därmen, der Magen sei ebenso gerüstet für Speisen und viele Gerichte und in die Gedärme gegossene Glaseln (Gläser), auf dass heute alle gut vorbereitet seien. Tischtücher auf den Tischen, Teller, Salz und in den Küchen, alles soll fertig sein, im Wasser ein frischer Schluck (eingekühlt), Becher voll mit unvermischtem Wein und an Märzenbier mangle es nicht. Heute - hört die Neuigkeit - ist Bacchus in der Stadt geboren, wie in einer Schwarzkuchl [= Schwarz-, Rauchküche] zur Zeit der finsteren Nacht, geboren fast wie damals, wie der Titan ihn herausgezogen hat. Herr Bacchus aber trat nicht in einem elenden Haus hervor noch zog er in einen erbärmlichen Bauernort. Die beste Küche - glaubt es alle - wurde dem Bacchus zum Ort der Geburt: Während er dort erschien, sobald er die Paläste der Könige emporstieg - aufgepasst: das Taratantara der Trompete, die Tamburine erwiderten Bumbum, Geigen und Zithern, die anderen Lauten ergänzten das alles, den Neugeborenen mit einer Krone schmückend. Dieser gab mir den Auftrag, durch Kreuzungen und Straßen die Nachrichten zu verbreiten bei allen Leuten auf der Welt. Wer trägt mir nun die Tausenden Worte in vollen Säcken hierher, damit ich erwähne - sofern das Schicksal es den Zuhörern gegönnt hätte - mit wie vielen Gebärden sie die Herzen gesehen hätten, die ich mit sehr vielen Worten nicht beschreiben kann. Habt ihr, meine Schar, die Neuigkeiten verstanden? Mehr täte ich euch sagen, wenn ich nicht weggehen müsste, denn alles kann ich in kurzen Worten nicht sagen, Immerhin wisst ihr jetzt, was solche Feste erfordern. Das mache jeder, dem Fräulein Pecunia dient, mit allem aus den Schenken soll die Geldbörse erleichtert werden. Und wenn es jemand an 
schwerem Geld mangelt zusammen mit verfügbaren Münzen, dem rate ich lieber zuhause zu bleiben und sich nicht anzumaßen als Mittelloser Bacchus zum Trinken einzuladen, denn er wird viele Haare vom Scheitel verlieren, mit seinen Kameraden wird er sich sehr wenige Becher leisten können. Jetzt werde auch ich Kirmes feiern, indem ich diese Becher austrinke. Hei, kommt her, Herren, da ist ein frischer Schluck. Doch zuvor werden wir die Ferkeln aus unseren Sackerln (Säcken) nehmen. Hier wohnt das Bratl (der Braten) und bei den Burschen bleibt der Kapaun, ei, komm hervor, Gefangene, heraus meine Flasche, lasst uns trinken. Aber doch ein klein bisschen ist jene auch zu ermahnen, es gilt, meine Herren, für alle, füllt unsere Gefäße wieder, nur heute, denn ich erweise mich schon weiser als alle. Weil meine Zunge - wie sichs gehört - jungen Falerner-Wein abbekommen hat, dient sie mir plötzlich tausendfach, um dies zu verkünden, tausend Arten, sag ich, die mein Geist sich jemals angeeignet hat. Oho, schon sind der Speisen genug in meine Därme gestopft, wohlan, genug, ich laufe, hei hei hei, meine guten Leute, lebt wohl. Ei ei, was ist das? Was ist das? O grausames Schicksal, warum verdirbst du meinen Trank?

17v solennitet] Festlichkeit

19v der ist Roth] die rote Farbe weist auf einen Kupferanteil im Silbergroschen und damit auf die Minderwertigkeit der Münze hin

20r Lunden] Gemeinde in Schleswig-Holstein, nahe der nördlichen Grenze des deutschen Sprachraums; vielleicht aber auch Anspielung auf das etwa $25 \mathrm{~km}$ von Nikolsburg entfernte Lundenburg (heute Břeclav)

21r Glormus]? Seyffried] Held der Siegfriedssage ableien] abbläuen, verprügeln

21v Quadragesima] 40-tagige Fastenzeit (als Personifizierung auf der Buhne)

22r Märck] Märkte Adeste ... Salutares] (lat.) Kommt, Schar, Vater Bacchus ruft, lauft bereit her, eilt, so verordnet er, befiehlt er, unser Führer wird allen heilbringende Gesetze geben

23r entschleisest] entschleisen: sich absetzen, entschlüpfen Ehr] ehe Pænitentz] Reue

23v exultiren] jubeln rechnet] rächt Inuolant ... Quadragesimo] sie schreien alle auf Quadragesima ein Sales cum 2 filijs] (lat.) Tanz mit zwei Söhnen

25r Italice ... rogo] (lat.) Italiener, sag mir, bitte Fugabo ... eum] (lat.) ich werde ihn mit Worten bald in die Flucht schlagen Dicor sic] (lat.) ich heiße so, hier allerdings fälschlich für dice sic [= sag so] Tristo ... commandare] (ital.) böse, schlechte Nervensäge, auf dass du gehängt wirst, was gibts da zum Herumbrüllen und mit uns Herumkommandieren Fristu ... commendare] pseudo-italienische Verballhornung des eben Gehörten Territus ... velint] (lat.) Siehst du, er schweigt tatsächlich eingeschüchtert. Die Stimme bleibt ihm im Hals stecken und er hat nicht einmal verstanden, was meine Worte sagen wollen.

26r content] zufrieden

26v Ludunt] (lat.) sie spielen

27v Hadern] Stofffetzen

28r parunt se] (lat.) sie gehorchen Picket] Piquet, Pikett: Kartenspiel für zwei Personen Trapalier] Trappelieren: tarockähnliches Kartenspiel der Barockzeit Pomalich] (bair.-österr.) langsam, gemütlich

31r Vernaczer] Vernatscher (Südtiroler) Wein Ducaischen] Tokajer Wein Capauner] Kapaune (Masthähne) Anten] Enten

31v Kantlen] (bair.österr.) Kannen 
32r conuinium] (lat.) Festmahl Vox ... inferius] Zampiers Stimme von oben, es wird unter dem Theater gesprochen; obwohl ein Gesang das Gespräch überlagert, wird die untere Stimme gehört

33v gehling] (bair.österr.) jäh, schnell

35r Charitet] Nächstenliebe benignitet] Freigebigkeit

37r Herbauken] Pauken stolprian] latinisierendes Scherzwort für ein Kraut bzw. Pulver zum Weiterstolpern Grachhus] einer der beiden römischen Volkstribune, die für eine gerechtere Agrarwirtschaft agitierten; in diesem Zusammenhang (absichtliche) Verwechslung mit Crassus? Prandium] (lat.) Frühstück, Zwischenmahlzeit

38v Comedunt ... ebrius] (lat.) Sie essen. Ein Betrunkener vertreibt sie Heu ... longum] (lat.) Ach ich Armer, was machen, wenn vier auf einen mit Prügeln einschlagen, ah, viel zerschlugen die Arme da drinnen. Ich würde nicht glauben, wenn ich nach diesem allein in der Weinstube wieder einen heben werde, denn mich erschreckt der Buchenstock. Anfangs waren wir allesamt gute Kameraden und wie Gefährten haben wir einander nur nette Worte gegeben. Als aber danach meine Gruppe vom Falerner-Wein betrunken war, kamen der mit Bacchus verwandte Bratwurst und Blutwurst von derselben Abstammung nach vielen Worten endlich zu Schlägen, Pratelius kippte sich nicht nur ein Glas in die Eingeweide und schon geriet der Verständige wie auch Redegewandte in Rage, Herr Bratwurst reizte mit stolzen Reden die Herzen, jetzt Italien schmähend, jetzt Böhmen aus dem Stegreif beleidigend, jetzt Griechenland beschimpfend, dann Spanien aus voller Kehle drohend, auch Deutsch: Komm raus, komm stechen, hauen, sehr viel (von dem Zeugs) gibt er von sich, Potz Hader, Potz Schanzen, beiß mir doch die Spitze von der Lanze. Obendrein - wie es der Brauch ist - schrie er fröhlich durch die aufgerissenen Fenster auf die Straßenecken mit Juchzen seinen Jubel hinaus. Das Haus selbst wurde schon klein, in jedem Winkel steckt ein Hintern und zornig mischt Tobsucht sich mit Wortgefechten: Kein gutes Wort fällt mehr beim Anstoßen. Inzwischen vom Ofen ist Blutwurst wutentbrannt dann bald mit Bratwurst vor die Tür gelaufen, wissend, dass dort ein harmloses Duell sein werde, bald lange Hier bricht der Text ab.

\section{Einzelstellenapparat für Texteigenheiten und editorische Eingriffe}

$1 \mathbf{w i r d t}$ wirdt. Anno 1654. 15. Febr[uarij] Orsum 24 Ao 1653 Decembris Finitum 19. Januarij 1654 Angaben zur Entstehung wurden nicht in den Edierten Text übernommen, (lat.) Im Jahr 1654. 15. Februar. Begonnen 24. Dezember 1653. Beendet am 19. Januar 1654

1v Das folgende nachgetragene Personenverzeichnis wurde nicht in den Edierten Text übernommen: Personæ quæ egerunt Nicolspurgi 15 Februarij Anno 1654] (lat.) Diejenigen Personen, die zu Nikolsburg am 15. Februar 1654 spielten. Prologus ... Nechamb]

Prologus, Daniel Nechamb

Zampir, Adalbertus Hofler

Tartarius Matthæus Kleiner

Belzabub Polentarius

Caramundius Martinus Forster

Pluto Folk
Saltantes pueri [(lat.) tanzende Jungen]

Philippus Kastner

Andreas Herdot

Ludouicus Suchentrunk

Ferdinandus Gott

Joannes Springer, \& Sin 
Micros Urbanus Konig

Riepert

Semele Christophorus De Suen

Hazala Hoffman Carolus

Raczala Preindl Laurentius

Nuncius Joannes Adamus Gruber

Poliphilus Andreas Schultz

Jokelius Dauid Olbricht

Bacchus Christophorus Kraus

Ludouicus König

Præco Georgius Suabensky

Quadragesima Christophorus de Suen

Pamphilus Paulus Woiner

Carinus Henricus Paumon

Calliodorus Thomas Lödrer

Syrus Joannes Benedictus Albin

Dromo Joannes Glosak

Codrus Andreas Schultz

Aluinkel Folk

Blind[s]chaw David Olbricht

Hansel Joannes Zagler

Dæmenetus Joannes Adamus Gruber

Castitas, Joannes Paumon

Temparantia Tobias Schitz

Mors Petrus Giorsius
6 Rustici saltantes [(lat.) tanzende Bauern]

Johannes Böm

Andreas Schultz

David Olbricht

Joannes Michna

Joannes Kreütz

Petrus Georgius

Lekertalius Joannes Adamus Gruber

Pratelius Reh

Guttburstius Paulus Woiner

Saufelius Carolus Walter

Ephebi Adamus Gruber

Joannes Herdot

Medicus [( lat.) Arzt] Daniel Nechamb

Ephebi medici [(lat.) Lehrlinge des Arztes]

Gros \& Glocz

Famulus medici [(lat.) Diener des Arzts]

Miltauer

Mendici in 2. actu [(lat.) Bettler im 2. Akt]

Folk, Simon Sacrua \& Laurentius Preindel

Chorus Andreas Grim, Joannes Herdot,

Franciscus Karpissek, Stephanus Sieber,

Paulus de Vena, Joannes Paumon,

Paulus Woiner, \& Nicolaus Vizam

Epilogus Daniel Nechamb

2v plura dicere] plura $x \times$ dicere Sofortkorrektur

4v [fett] \& fidem finem Sofortkorrektur

6r verhindert ... Gast] Zusatz von späterer Hand Theatro hinunderstürzen] Theatro will hinunderstürzen Streichung von späterer Hand heüt] Korrektur von späterer Hand, Gestrichenes unleserlich (heit?) oder grossen] oder grossen Streichung von späterer Hand von Bacchi] von Baeeli-Bacchi Sofortkorrektur

6v Entlich] letztlich Ersetzung von späterer Hand Bacchi ... Eitelkeit] sein Macht vndt großeEitelkeit Ersetzung von späterer Hand waß ist dan] was ist Ersetzung von späterer Hand

7r andre Strassen] fremde Strassen Ersetzung von späterer Hand Du magst] Ha Ha Ha, Du magst Sofortkorrektur des Zeilensprungs

7v ist dan dein] ist dein Einfügung von späterer Hand nicht lenger Stehen] nicht Stehen Einfügung von späterer Hand hab ichs] habs ich Korrektur von späterer Hand

8r langem Rath] Blatt zu stark beschnitten, gem ergänzt das volk] as ergänzt fresserey] esse ergänzt lezten] en ergänzt

9r Tot gar nicht] dot nicht Korrektur und Einfügung von späterer Hand

9v kann erfüllen] bald erfüllen Ersetzung von späterer Hand

10r Erden hats] Erden has hofortkorrektur Gott selbst] Gott selbst Sofortkorrektur sey Böß] sey Guts Böß Sofortkorrektur gnossen werden:] gnossen werden: + Markierung 
von späterer Hand oder waß einen] aber waß ein einen Sofortkorrektur Sünden] Süden Emendierung

10v Oder ihm vor] Oder sie vor Korrektur und Einfügung von späterer Hand Rathet ... Reimet] Rathet ich Waß ihr ë̈ch dichtet Korrektur und Einfügung von späterer Hand mit ... meinet] Belzebub ficht woll Korrektur wohl von späterer Hand wird volgen] wird folg volgen Sofortkorrektur

11r mehr achten] mam mehr achten Sofortkorrektur (?) Auch wo] Ach Auch wo Sofortkorrektur

12r erdichten] eimbilden Korrektur und Einfügung von späterer Hand erkennen] erkennen + Markierung von späterer Hand

12v Schmerzen] Smerzen Emendierung erefnen] erefnen + Markierung von späterer Hand

13v darffst vnß nicht] darffst nicht Einfügung von selber (?) Hand mög haben] kint krigen Korrektur und Einfügung von späterer Hand alle beid] alle beüd beid Korrektur und Einfügung von späterer Hand

14r bin worden] bin worden + Markierung von späterer Hand zu gsicht] wohl fälschlich für zu gschickt

16r Gsichten] Gsichten Sofortkorrektur mit mir] mit mich mir Sofortkorrektur

17v illa monenda] faska monenda Korrektur und Einfügung von späterer Hand nam ago iam] Korrektur und Einfügung von späterer Hand hæc parlandi] Korrektur und Einfügung von späterer Hand

18r keklich vor] keklich und vor Sofortkorrektur vnß getroffen] mich getroffest

18v kochen ohne Häffen] vmb] Mich und vmb Sofortkorrektur

19r selbst lachen] lachen Korrektur und Einfügung von späterer Hand

19v leicht glaub] leicht Korrektur und Einfügung von späterer Hand Bewerlein] Bewerlein + Markierung von späterer Hand krochen werden] krochen werden + Markierung von späterer Hand Ich schätze] Ich setze schätze Sofortkorrektur

20r gwarnet] gwrnet Emendierung Also vnß arme] Also mit Korrektur und Einfügung von späterer Hand speisen Mochen] speisen Korrektur und Einfügung von späterer Hand

20v lenger bleiben] lenger stehen Korrektur und Einfügung von späterer Hand freintlich] Eilith Sofortkorrektur (?) mir wirds] wirds mir richtige Reihenfolge durch selbe (?) Hand mit Ziffern markiert belohnen] verlohnen Korrektur und Einfügung von späterer Hand du bist] du xist bist Sofortkorrektur

21r Wo] istein Wo Sofortkorrektur

22r Höchsten Neygen] Gutten Neygen Korrektur und Einfügung von späterer Hand mein Regierung vnd Regiment] mein Regiment vnd Regierung richtige Reihenfolge durch selbe (?) Hand mit Ziffern 1-4 markiert hofflich] frölich Korrektur und Einfügung von späterer Hand

22v Drost vnd vreit] Blatt an Oberkante beschnitten, teilweise nicht leserlich

25r stehen] gehen Korrektur und Einfügung von späterer Hand faucibus illi] faucibus haret illi Sofortkorrektur (?)

25v bös] fehlt, sinngemäß emendiert 
26v nacher zuken] darzu alsø zuken Korrektur und Einfügung von späterer Hand Kreützer] Krützer Schreibversehen emendiert

27r finde kein] kein finde richtige Reihenfolge durch selbe (?) Hand mit Ziffern markiert das wohl] wohl das richtige Reihenfolge durch selbe (?) Hand mit Ziffern markiert

27v klagen] sagen klagen ewerige] $x$ xखge Pxxx Korrektur und Einfügung von späterer Hand

28r Bundschaw] Allkiminitus hier und in Folge von späterer Hand konsequent ersetzt zum Wein] auf den Wein Korrektur und Einfügung von späterer Hand vnß nicht schlagen] vnß schlagen Einfügung von späterer Hand seit frisch] Spih\# frisch Korrektur und Einfügung von späterer Hand

28v mir es] mir Einfügung von späterer Hand schnuptawak] schuptawak Emendierung Solchen Tabak] सatchen Tawak Korrektur und Einfügung von späterer Hand

29r Ja wolt] wolt Einfügung von späterer Hand HANSEL.] Hanßel. Emendierung zur Vereinheitlichung (auch in weiterer Folge) Ich hab ... offen] Zeilentausch durch Nummerierung von späterer Hand markiert

29v eilet nur] eilet hor Emendierung

32r gleich neigen] neigen Korrektur und Einfügung von späterer Hand

31v darauff ir] darauff wir sinngemäß emendiert

33v verendest] verderbestKendest Korrektur und Einfügung von selber (?) Hand, Emendierung Oder ... speiß] Oder ... speiß Sofortkorrektur verderbest] sterbest verderbest Sofortkorrektur (?) gesagt] gethan gesagt Sofortkorrektur (?)

34r Gelds hab kein] Geld kein Sofortkorrektur und Einfügung von selber Hand (?)

34v bekommen] beysammen bekommen Sofortkorrektur (?) forcht] fercht Sofortkorrek$\operatorname{tur}(?)$

35v Gott dank] Gott dak Emendierung Vnd euch] euch Korrektur und Einfügung von späterer Hand STINKFISL.] Allkirmius Korrektur und Einfügung von späterer Hand meinen alten]

36r CODRUS.] Allwinket ersetzt durch Altsecius, auch dieses gestrichen und mit NB versehen, Codrus am rechten Rand ALTSECIUS.] Godrus hier und zu Beginn von $36 v$ Korrektur und Einfügung von selber Hand

37v schwatzer] swatzer sinngemäß emendiert

38v schlagen] schlagen Sofortkorrektur 


\section{Editionskriterien}

- Die Groß- und Kleinschreibung der Handschrift wird (mit Ausnahme des Titels) grundsätzlich auch bei heute ungewöhnlicher Setzung beibehalten, sofern sie deutlich unterscheidbar ist. Zweifelsfälle allerdings bei mangelnder Unterscheidbarkeit von Majuskel und Minuskel (d/D), bei Größenvarianz (a/A, f/F, g/G, h/H, k/K, n/N, o/O, u/U, v/V, z/Z) oder mehreren Minuskelvarianten ( $\mathrm{g}, \mathrm{h}, \mathrm{w})$ werden unmarkiert der zeitüblichen Schreibung angeglichen. Die Versanfänge werden (wie wohl intendiert) konsequent in Majuskeln wiedergegeben.

- $\quad$ Die Getrennt- und Zusammenschreibung richtet sich grundsätzlich nach der Vorlage; in Zweifelsfällen bei geringem Spatium wird die Schreibung an die orthographischen Gewohnheiten der Zeit angepasst.

- $\quad$ Binnenmajuskeln (v.a. P, R) werden nicht wiedergegeben.

- Die Interpunktion folgt, auch bei offensichtlichen Kopisten- oder Druckfehlern, der Vorlage.

- $\quad$ Die Silbentrennung am Zeilenende der Vorlage wird nicht übernommen.

- Schreibökonomische Abkürzungen im Text werden, sofern sie sich eindeutig aus dem Kontext erklären, prinzipiell unmarkiert aufgelöst.

Dies gilt bei deutscher Kursive für:

Suspensionen mit Punkt bei Eigennamen, Konjunktionen, Präpositionen, Regiebezeichnungen / geschwänztes End-e als Abbrechungszeichen für -en / $d$ in Kombination mit einem dem $z$ ähnelnden Zeichen für das bzw. $d a \beta$ (kontextuell angepasst) / $d$ mit zusätzlicher nach oben gezogener Schleife für der / Nasalstrich als Doppelungszeichen bei $n$ und $m$.

Bei Latina werden folgende Abkürzungen unmarkiert aufgelöst:

Abbrechungen bei -um, -em, -am (Querstrich ersetzt $m$ ), -us, -que (tiefer gestelltes 3 ersetzt $u e$ ), -us (durch angehängtes tiefer gestelltes Zeichen 9 ersetzt), -ur (durch angehängtes Zeichen 3 ersetzt) / durch hochgestelltes Zeichen 2 markierte Kontraktionen z.B. bei Joes (Joannes), oes (omnes), Dni (Domini) oder tn (tamen) werden ersetzt, bei quis wird qs mit Unterstrich aufgelöst.

- Umfangreichere Auflösungen werden mit spitzen Klammern « s markiert.

- Rollenbezeichnungen werden in Majuskeln wiedergegeben und einheitlich vom Sprechtext mit Punkt und Spatium getrennt; Abkürzungen werden aufgelöst, unterschiedliche Schreibweisen gemäß dem Rollenverzeichnis normalisiert.

- $\quad$ Regieanweisungen werden kursiv gesetzt.

- Einfügungen, Korrekturen und Auslassungen von Editorenhand werden mit eckiger Klammer [ ] markiert.

- $\quad$ Schaft-s und rundes $s$ werden als Allographe einheitlich mit $s$ wiedergegeben.

- Die mit Antiqua oder lateinischer Schreibschrift von der deutschen Kurrente abgehobenen lateinischen Teile werden in der Edition graphisch nicht differenziert.

- Seitenzahlen werden mit spitzen Klammern 〈〉 in den Text eingefügt und bei Absatzwechsel dem letzten Wort(teil) der vorangehenden Seite nachgestellt.

- $\quad$ Doppelpunkte nach Szenen- und Akteinteilung wurden einheitlich getilgt.

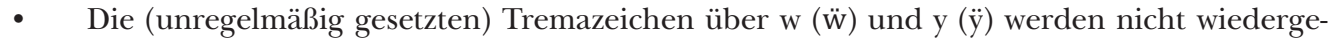
geben. 


\section{Assoz. Prof. Mag. Dr. Christian Neuhuber}

Franz-Nabl-Institut für Literaturforschung, Universität Graz, Elisabethstr. 30/I, A-8010 Graz, Österreich

christian.neuhuber@uni-graz.at

Christian Neuhuber ist Assoziierter Professor für Neuere deutschsprachige Literatur an der Universität Graz. Er studierte Germanistik, Medien, Kunstgeschichte und Deutsch als Fremdsprache in Graz und lehrte viele Jahre an der Palacký-Universität Olmütz. Seine Schwerpunkte liegen in der Literatur des Barock bis zur Gegenwart mit Fokus auf Intermedialität, Editionsphilologie, Theatergeschichte und Dialektkultur. Aktuelle Publikation: Bairisch-österreichische Dialektliteratur vor 1800. Eine andere Literaturgeschichte (mit S. Edler und E. Zehetner, Wien 2019). 